\title{
Deep sequencing-based comparative transcriptional profiles of Cymbidium hybridum roots in response to mycorrhizal and non-mycorrhizal beneficial fungi
}

\author{
Xiaolan Zhao ${ }^{1+}$, Jianxia Zhang ${ }^{2 \dagger}$, Chunli Chen ${ }^{1}$, Jingze Yang ${ }^{1}$, Haiyan Zhu', Min Liu ${ }^{1}$ and Fubing Lv $^{3 *}$
}

\begin{abstract}
Background: The Orchidaceae is one of the largest families in the plant kingdom and orchid mycorrhizae (OM) are indispensable in the life cycle of all orchids under natural conditions. In spite of this, little is known concerning the mechanisms underlying orchid- mycorrhizal fungi interactions. Our previous work demonstrated that the non-mycorrhizal fungus Umbelopsis nana ZH3A-3 could improve the symbiotic effects of orchid mycorrhizal fungus Epulorhiza repens ML01 by co-cultivation with Cymbidium hybridum plantlets. Thus, we investigated the C. hybridum transcript profile associated with different beneficial fungi.

Results: More than 54,993,972 clean reads were obtained from un-normalized cDNA library prepared from fungal- and mock- treated Cymbidium roots at four time points using RNA-seq technology. These reads were assembled into 16,798 unique transcripts, with a mean length of $1127 \mathrm{bp}$. A total of 10,971 (65.31\%) sequences were annotated based on BLASTX results and over ninety percent of which were assigned to plant origin. The digital gene expression profiles in Cymbidium root at 15 days post inoculation revealed that 1674,845 and 1743 genes were sigificantly regulated in response to ML01, ZH3A-3 and ML01+ ZH3A-3 treatments, respectively. Twenty-six genes in different regulation patterns were validated using quantitative RT-PCR. Our analysis showed that general defense responses were co- induced by three treatments, including cell wall modification, reactive oxygen species detoxification, secondary biosynthesis and hormone balance. Genes involved in phosphate transport and root morphogenesis were also detected to be up-regulated collectively. Among the OM specifically induced transcripts, genes related to signaling, protein metabolism and processing, defense, transport and auxin response were identifed. Aside from these orchid transcripts, some putative fungal genes were also identified in symbiotic roots related to plant cell wall degradation, remodeling the fungal cell wall and nutrient transport.

Conclusion: The orchid root transcriptome will facilitate our understanding of orchid - associated biological mechanism. The comparative expression profiling revealed that the transcriptional reprogramming by OM symbiosis generally overlapped that of arbuscular mycorrhizas and ectomycorrhizas. The molecular basis of OM formation and function will improve our knowledge of plant- mycorrhzial fungi interactions, and their effects on plant and fungal growth, development and differentiation.
\end{abstract}

Keywords: Root transcriptome, Digital gene expression, Plant mycorrhizal symbiosis, Cymbidium hybridum, Epulorhiza repens ML01, Umbelopsis nana ZH3A-3

\footnotetext{
* Correspondence: Ivfubing2014@sina.com

${ }^{\dagger}$ Equal contributors

${ }^{3}$ Guangdong Key Laboratory of Ornamental Plant Germplasm Innovation and

Utilization, Environmental Horticulture Research Institute, Guangdong

Academy of Agricultural Sciences, East 1st Street 1, Jinying Road, Tianhe

District, Guangzhou 510640, People's Republic of China

Full list of author information is available at the end of the article
}

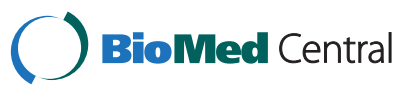

(c) 2014 Zhao et al.; licensee BioMed Central Ltd. This is an Open Access article distributed under the terms of the Creative Commons Attribution License (http://creativecommons.org/licenses/by/4.0), which permits unrestricted use, distribution, and reproduction in any medium, provided the original work is properly credited. The Creative Commons Public Domain Dedication waiver (http://creativecommons.org/publicdomain/zero/1.0/) applies to the data made available in this article, unless otherwise stated. 


\section{Background}

All orchids produce minute, endosperm- lacking seeds and are dependent on fungal colonization for germination and growth into an underground heterotrophic, achlorophyllous stage called a protocorm under natural conditions $[1,2]$. After this fully mycotrophic stage, most species shift to autotrophy at adult stage with the development of photosynthetic organs, but approximately 200 species worldwide stay fully mycoheterotrophic (MH) [3]. Recently, some chlorophyllous species in Orchidaceae were verified to obtain carbon at adult stage not only from their photosynthetic activity, but also from mycorrhizal fungi, which were called mixotrophs (MX) [4,5]. Among these, several terrestrial orchids such as C. lancifolium and $C$. goeringii were shown to be MX nutritional mode through isotopic analyses [6]. The dependency of green orchids on mycorrhizal fungi throughout their life cycle prompts us to study these mycorrhizal interactions in more detail.

In nature, orchids largely associate with members of the 'rhizoctonia' complex, which contains three now taxonomically disparate Agaricomycetes ( $1 / 4$ Hymenomycetes) taxa: Sebacinales, Ceratobasidiaceae and Tulasnellaceae. Tulasnellaceae are the most frequently found 'rhizoctonias' in green orchids [1,3]. Besides orchid mycorrhizal fungi (OMF), recent studies also demonstrated that isolates of Umbelopsis, as non-mycorrhizal beneficial endophytes, probably co-existed in the roots of wild orchids $[7,8]$.

C. hybridum collectively contains a large number of cultivars with large flowers. Over 20 species in Cymbidium, including C. sinense, C. goeringii, C. faberi, C. ensifolium and $C$. kanran, were used in their breeding programs. In our previous work, one OMF isolate ML01 and one nonmycorrhizal beneficial isolate ZH3A-3 were isolated from roots of wild C. spp. adult plants and identified as E. repens [ITS accession number of ML01 in GenBank: KJ499806; also referred to Tulasnella-like Rhizoctonia] and $U$. nana [ITS accession number in GenBank: HM214447], respectively. Here, we present that ML01 forms typical mycorrhiza with C. hybridum. Individual (ML01, ZH3A-3) or combinative (ML01 + ZH3A-3, MZ) inoculation significantly improved the vegetative growth of C. hybridum plantlets compared with mock-inoculated controls.

Although orchid mycorrhizal (OM) symbiosis is an important feature in the life cycle of orchids, it has long been considered to be an atypical mycorrhizal association, with the fungus deriving little benefit from the orchid host [3]. But Cameron et al. $[9,10]$ reported that approximately $0.4-3.0 \%$ of the labeled carbon provided to the orchids was passed to the fungal partner $[9,10]$. Thus adult orchid mycorrhizas may represent a truly mutualistic interaction similar to ectomycorrhizae (ECMs) and arbuscular mycorrhizae (AMs) associations [3].
Compared with the numerous transcriptional analyses to identify genes involved in AM [11-15] and ECM symbiosis [15-17], the molecular mechanisms behind OM symbiosis are still poorly understood [18-21]. Recently, different gene expression or proteome changes of orchid protocorms in response to mycorrhizal fungi were studied and mutualistic plant-fungus relationship was suggested [19-21]. As for orchids at the adult stage, Valadares [20] used RNA-seq to determine the gene expression profile of wild Oeceoclades maculata mycorrhizal roots in comparison to non-mycorrhizal controls [22]. While this study provides new insights into our understanding of the OM symbiosis for adult orchids, the symbiosis seems to be highly complex as wild orchids generally associate with multiple symbionts even within a single root [23]. Although genomic sequence resources currently available for orchids are limited, large expressed transcripts from Phalaenopsis aphrodite, P. equestris, $P$. bellina, Oncidium Gower Ramsey, Erycina pusilla and $C$. sinense were generated in recent years with the rapid advances in DNA sequencing technology known as next-generation sequencing (NGS or massively parallel sequencing) and the development of bioinformatic processes, especially for de novo assembly without reference genome information [24-26]. Whereas no genetic information on orchid mycorrhizal fungi was available when our analyses began, large numbers of assembled transcripts and the genome information of $T$. calospora had been recently generated as part of a DOE JGI Community Sequencing program. This work has allowed us to assign some putative fungal genes to mycorrhizal fungi ML01 by Blastn searches of these data. In this paper, we used NGS approach and Illumina Digital Gene Expression (DGE) technology to obtain genomewide insight into the transcriptomic responses of $C$. hybridum under specific interactions with mycorrhizal or/and other beneficial fungi. To our knowledge, this represents the first genome-wide gene expression profile of orchid plants in response to mycorrhizal or nonmycorrhizal fungi. The data enabled us to get new insight into the mechanisms underlying plant responses to mycorrhizal and non-mycorrhizal beneficial fungi. The transcriptome for $C$. hybridum could also be used as an important resource for exploring other biological processes in orchids.

\section{Methods}

\section{Biological materials and inoculation}

The micro-propagated plantlets of $C$. hybridum 'Golden Boy' were provided by the Guangdong Key Lab of Ornamental Plant Germplasm Innovation and Utilization, China. The propagation procedure for orchid plantlets was described in [8]. The two fungal isolates ML01 and ZH3A-3 were preserved in the Guangdong Key Laboratory 
for Innovative Development and Utilization of Forest Plant Germplasm. Inocula were produced by growing each strain on $90 \mathrm{~mm}$ Petri dishes containing potato-dextrose agar (PDA) for 10 days.

The plantlets with $3-4$ roots about $2.5-3 \mathrm{~cm}$ long were then transferred to DE basal medium, an in vitro mycorrhizal induction medium in orchids [27]. The cocultivation DE medium contained $1.0 \mathrm{mM} \mathrm{CaCl}_{2}, 0.5 \mathrm{mM}$ $\mathrm{MgSO}_{4}, 1.0 \mathrm{mM} \mathrm{K} \mathrm{SO}_{4}, 0.4 \mathrm{mM} \mathrm{KH_{2 }} \mathrm{PO}_{4}, 100 \mu \mathrm{M} \mathrm{FeS0} 0_{4}$, $25 \mu \mathrm{M} \mathrm{H}_{3} \mathrm{BO}_{4}, 33 \mu \mathrm{M} \mathrm{MnCl}, 2.8 \mu \mathrm{M} \mathrm{ZnSO}_{4}, 1.0 \mu \mathrm{M}$ $\mathrm{NaMoO}_{4}, 140 \mu \mathrm{M} \mathrm{Na}{ }_{2}$ EDTA, supplemented with yeast extract $1 \mathrm{~g} \cdot \mathrm{L}^{-1}$, soluble starch $9 \mathrm{~g} \cdot \mathrm{L}^{-1}$ and agar $6 \mathrm{~g} \cdot \mathrm{L}^{-1}$. Each plantlet was inoculated with a $7 \mathrm{~mm}$ plug excised from an edge of an actively growing colony on PDA of strain ML01, ZH3A-3 or ML01+ ZH3A-3.The control plantlets were mock-inoculated with a plug excised from a PDA plate without fungus. All the treated and control plantlets were then incubated under a photoperiod of $16 \mathrm{hrs}$ light at a temperature of $22^{\circ} \mathrm{C}$.

\section{Symbiotic effects on vegetative growth of $C$. hybridum}

After 45 days post- inoculation (dpi), ninety plantlets of each treatment were totally harvested and randomly divided into three groups, which represented three biological replicates. The symbiotic effects on the vegetative growth of the hosts were assessed by total increased fresh weight and dry biomass of the plantlets. The percentage of root growth (PRG) and mycorrhizal dependency (MD) were also compared among different treatments. MD was calculated by the following formula: (shoot dry wt. of mycorrhizal plants- shoot dry wt. of non-mycorrhizal plants) $\times 100 /$ shoot dry wt. of mycorrhizal plants as described in [28]. For statistical analysis of data, SPSS v13.0 was employed for one-way analysis of variance (ANOVA) and comparisons among means were made using Duncan's multiple range test, calculated at $\mathrm{p}<0.05$.

\section{Root staining and histology}

The successful inoculation with strains ML01 and ZH3A-3 and the absence of fungal contaminants in mock-treated roots were confirmed by trypan blue staining [8]. To confirm their respective colonization pattern, semi-thin sections of root samples for each treatment were prepared and stained with a $0.05 \%$ aqueous solution of toluidine blue for light microscopy (Olympus-BX51, Olympus Corp., Tokyo, Japan).

\section{Reference cDNA library construction}

At 1, 3, 15 and $30 \mathrm{dpi}$, orchid roots of MZ- treated or mock-inoculated control plantlets were harvested by carefully removing the substrate and mycelia, and the samples were frozen in liquid nitrogen and stored at $-80^{\circ} \mathrm{C}$. Total RNA from each sample was extracted separately with Column Plant Total RNAout kit according to the manufacturer's protocol (TIANDZ Co., Beijing, China). The RNA was treated with DNase (Takara, China) and then quantified using a NanoDrop $2000^{\mathrm{sin}}$ spectrophotometer (Thermo Scientific, Waltham, MA, USA). Equal amounts of total RNA from MZ- treated and mockinoculated samples at each time point were pooled to produce minimum $20 \mu \mathrm{g}$ total RNA for constructing a cDNA library for establishing the reference transcriptome.

\section{mRNA-sequencing and cDNA de novo assembly}

The library construction and sequencing were performed by the Beijing Genomics Institute (BGI) (Shenzhen, China) and the general experimental pipeline was summarized by previously published papers [29,30]. First, the cDNA library was pair-end sequenced by Illumina HiSeq2000 (90 bp single read module). After removing adaptor sequences, empty reads and low quality sequences (reads with unknown sequences ' $N$ '), we obtained the clean reads for de novo assembly. Three de novo assembly software were used including SOAPdenovo with optimized $k$-mer length of 41, ABySS [31] with K-mer length of 49 and Trinity [32] (http://trinityrnaseq.sourceforge.net/) with default $k$-mer length of 25 . Sequence directions of the resulting unigenes were validated by blastx alignment (e-value $<0.00001)$ between unigenes and public protein databases with a priority order of NR (non-redundant protein sequences in NCBI), Swiss-Prot, Kyoto Encyclopedia of Genes and Genomes database (KEGG), and COG. When a unigene happens to be unaligned to none of the above databases, ESTScan will be introduced to predict its coding regions as well as to decide its sequence direction.

After sequencing and assembling, we obtained three de novo assembled transcriptome database with three different assembly methods. The number of assembled transcripts, total bases of transcripts, average length of all unigenes, N50, number of long-transcripts $(\geq 1 \mathrm{~kb})$, and number of reads that could be mapped back to transcripts (RMBT) were compared to evaluate the assembly quality with different methods and select the optimum reference transcriptome for further study. The expression level of unigene was measured by the number of clean reads mapped to each annotated unigene normalized to RPKM (reads per Kb per million reads) [33] and adjusted using an additional normalizing factor [34].

\section{Functional annotation}

The protein functional annotation of unigenes was given according to the known proteins with the highest sequence similarity by Blastx to public protein databases mentioned above. Domain-based alignments were carried out against the COG database to predict and classify possible functions of unigenes. We further 
used the Blast2GO program (www.blast2go.org) to get $\mathrm{GO}$ annotation of unigenes.

\section{Validation of the reference assembly}

To validate the assembled reference transcripts, 18 unigenes were randomly chosen for further RT-PCR and Sanger sequencing. Gene specific primers were designed according to the assembled transcripts with primer premier software (version 5.0) (Additional file 1: Table S1). The reaction was performed in $25 \mu \mathrm{l}$, containing $0.5 \mu \mathrm{l} \mathrm{cDNA}$ template, $12.5 \mu \mathrm{l}$ Ex Taq Mix (TAKARA, Qingdao, China), $1 \mu \mathrm{l}$ of each $20 \mu \mathrm{M}$ forward and reverse gene-specific primers and $10 \mu \mathrm{l}$ of PCR-grade water. Touch-down PCR reactions were performed as follows: $95^{\circ} \mathrm{C}$ for 5 min before cycling 30 rounds of $94^{\circ} \mathrm{C}$ for $30 \mathrm{~s}, 65^{\circ} \mathrm{C}$ for $30 \mathrm{~s}$ (decreasing $0.5^{\circ} \mathrm{C}$ in every cycle) and $72^{\circ} \mathrm{C}$ for $1 \mathrm{~min} 30 \mathrm{~s}$ - followed by 15 cycles of $94^{\circ} \mathrm{C}$ for $30 \mathrm{~s}, 54^{\circ} \mathrm{C}$ for $30 \mathrm{~s}$ and $72^{\circ} \mathrm{C}$ for $1 \mathrm{~min} 30 \mathrm{~s}$ and finally a $72^{\circ} \mathrm{C}$ extension step for $10 \mathrm{~min}$. The specificity of products was inspected by $1 \%$ agarose gel electrophoresis before they were purified with Ezgene ${ }^{\text {mm }}$ Gel/PCR Extraction Kit (DC3511-02, Biomiga). The purified PCR products were Sanger-sequenced by the Beijing Genomics Institute (BGI) (Shenzhen, China).

\section{Identification of differentially expressed genes (DEGs) using Illumina short reads}

To perform quantitative comparisons of the transcript variation with respect to different beneficial fungi, total RNA samples generated from roots treated with ML01 (CyEX21), ZH3A-3 (CyEX22) or ML01 + ZH3A-3 (CyEX23 ) and mock-inoculated controls (CyEX20) at $15 \mathrm{dpi}$ were used to construct un-normalised cDNA libraries which were sequenced by Illumina HiSeq2000 (100 bp single read module). The cDNA library construction, sequencing, transcript profiling and mapping back to the newly assembled reference transcriptome with Trinity were carried out as a custom service (Beijing Novogene Bioinformatics Technology Co., Ltd., Beijing, China). The expression level of each assembled transcript in different samples was measured as RPKM values. SeqMap [35] was used for read mapping and rSeq [36] was applied for RPKM based expression measurement. Abundance data from different samples were collected for each transcript. In our work, the changes in relative abundance for unigenes between two samples were screened with the threshold: q-value $\leq 0.005$ and $\log 2$ Ratio $\geq 1$ or $\leq-1$.

\section{Quantitative RT-PCR (qRT-PCR) validation}

qRT-PCR was further carried out to analyze the expression of twenty- six DEGs identified by RNA-seq technology. Gene specific primers were designed according to the cDNAs with Primer Premier software (version 5.0) (Additional file 2: Table S2). For RNA extraction of each treatment, three biological replicates were collected independently and immediately frozen in liquid nitrogen. One microgram of total RNA was reverse-transcribed in a $20 \mu \mathrm{L}$ reaction mixture from a PrimeScript II 1st Strand cDNA Synthesis Kit (Takara, Dalian, China). qRT-PCR was performed in a $25 \mu \mathrm{L}$ reaction mixture containing $2 \times$ SYBR Master Premix Ex Taq II $12.5 \mu \mathrm{L}$ (Takara, Dalian, China), $1 \mu \mathrm{L}$ of cDNA template (1:5 dilution), and $1 \mu \mathrm{L}$ of each corresponding primer for the gene of interest. qRT-PCR of three biological replicates for each sample was performed using a LightCycler 480 II System with its relative quantification software (ver. 1.2) based on the deltadelta-Ct method (Roche). qRT-PCR was performed for $5 \mathrm{~s}$ at $95^{\circ} \mathrm{C}, 10 \mathrm{~s}$ at $56^{\circ} \mathrm{C}$, and $20 \mathrm{~s}$ at $72^{\circ} \mathrm{C}$. The cDNA samples were standardized to two reference genes: B21 (Unigene11515-all) and B24 (Unigene1346-all).

\section{Results}

Co-cultivation of $C$. hybridum plantlets with different fungi and their respective symbiotic effects on host vegetative growth

When co-cultivated with C. hybridum plantlets, the hyphae of the two isolates ML01 and ZH3A-3 began to grow at $2 \mathrm{dpi}$ and first contacted the hosts' roots at 4 dpi. After $15 \mathrm{dpi}$, the co-cultivation media of plantlets inoculated with ML01 changed from transparent to opaque, whereas the actively growing white fluffy hyphae of isolate ZH3A-3 fully covered the plate. The hyphal growth of isolate ZH3A-3 was retarded by the co-inoculated isolate ML01, which showed space at the colony margin (Additional file 3: Figure S1). After 45 dpi, ML01, ZH3A-3 and MZ treatments all significantly improved the total fresh weight and dry biomass of C. hybridum plantlets compared to the control (Table 1).

\section{Detection the colonization feature of different beneficial fungi on roots of $C$. hybridum plantlets}

In an initial observation, the hyphae of two isolates began to contact with orchids roots at $4 \mathrm{dpi}$. After that time point, we stained the host's roots with each treatment every two days to monitor the colonization process of different fungi and the root staining results of each treatment at $6,10,15$ and $30 \mathrm{dpi}$ were presented in Additional file 4: Figure S2. At 6 dpi, the first contacted roots were stained to confirm the hyphal penetration by isolates ML01 or ZH3A-3. After $15 \mathrm{dpi}$, orchid roots were extensively colonized by these fungi. At $30 \mathrm{dpi}$, the symbiotic roots of orchid plantlets showed uneven staining owing to the rapid growth of roots. To confirm the root staining results and characterize the exact colonization pattern of 
Table 1 Effect of inoculation with Epulorhiza repens isolate ML01and/or Umbelopsis nana isolate ZH3A-3 on the growth parameters of Cymbidium hybridum plantlets at $\mathbf{4 5}$ dpi

\begin{tabular}{lccccccc}
\hline Treatment & PRG (\%) & Leaf FW (g) & Root FW (g) & Increased FW (g) & Leave DW (g) & Total DW (g) & MD (\%) \\
\hline control & 22 & $0.76 \pm 0.09^{\mathrm{b}}$ & $0.35 \pm 0.13^{\mathrm{d}}$ & $0.34 \pm 0.11^{\mathrm{d}}$ & $0.07 \pm 0.01^{\mathrm{b}}$ & $0.09 \pm 0.02^{\mathrm{c}}$ & 0 \\
ML01 & 53.3 & $1.19 \pm 0.14^{\mathrm{a}}$ & $0.49 \pm 0.20^{\mathrm{cd}}$ & $0.79 \pm 0.17^{\mathrm{bc}}$ & $0.13 \pm 0.04^{\mathrm{a}}$ & $0.17 \pm 0.04^{\mathrm{ab}}$ & 46.5 \\
ZH3A-3 & 62.5 & $1.00 \pm 0.12^{\mathrm{a}}$ & $0.71 \pm 0.13^{\mathrm{ab}}$ & $0.84 \pm 0.15^{\mathrm{ab}}$ & $0.12 \pm 0.03^{\mathrm{a}}$ & $0.17 \pm 0.04^{\mathrm{ab}}$ & 41.7 \\
ML01 + ZH3A-3 & 79.0 & $1.11 \pm 0.12^{\mathrm{a}}$ & $0.89 \pm 0.21^{\mathrm{a}}$ & $0.99 \pm 0.14^{\mathrm{a}}$ & $0.14 \pm 0.05^{\mathrm{a}}$ & $0.20 \pm 0.07^{\mathrm{a}}$ & 50.0 \\
\hline
\end{tabular}

All the data were mean of three biological replicates, \pm standard deviation. (FW: fresh weight; DW: dry weight; MD (\%): percentage of mycorrhizal dependency; PRG (\%): the elongated root number/total root number $\times 100$ ). Values followed by different lower-case letters within a column are significantly different at $P<0.05$ according to DMRT.

these beneficial fungi, we further analyzed the microscopic structure of the formed symbionts at $15 \mathrm{dpi}$.

Root cross sections of $C$. hybridum plantlets generally included root hairs, velamen (2-3 layers), exodermis (1 layer), cortex (10-13 layers), endodermis (1 layer), pericycle (1 layer), vascular cylinder and pith (Figure 1A). At $15 \mathrm{dpi}$, typical pelotons were formed by isolate ML01 in the host cortex cells (Figure 1D) whereas hyphae of isolate ZH3A-3 only colonized the velamen cells at regular intervals (Figure 1B). Roots co-inoculated with isolates ML01 and ZH3A-3 contained newly formed and degenerated pelotons, and also typical aggregated hyphae of isolate ZH3A-3, demonstrating the co-infection of two isolates (Figure 1C). None of these fungal structures were observed in control root tissue (Figure 1A).
Root transcriptome profile of $C$. hybridium generated by mRNA-sequencing (RNA-seq)

Up to date, none of genome sequences for Orchidaceae was available in public database. RNA-seq, a cost-effective and highly efficient next-generation sequencing technology, provides high throughput and is therefore commonly used for de novo transcriptome assemblies in non-model species, including orchid species [26,37-39]. To analyze the transcript variation in C. hybridium colonized by beneficial fungi, pooled total RNA from eight samples including MZ-treated and mock-inoculated plantlets at each time point were used to generate an informative reference transcriptome database. Totally, 4,949,457,480 base pairs raw data were generated using the Illumina HiSeq2000, yielding 54,993,972 clean reads that were $90 \mathrm{bp}$ in length. The raw reads data are available at the
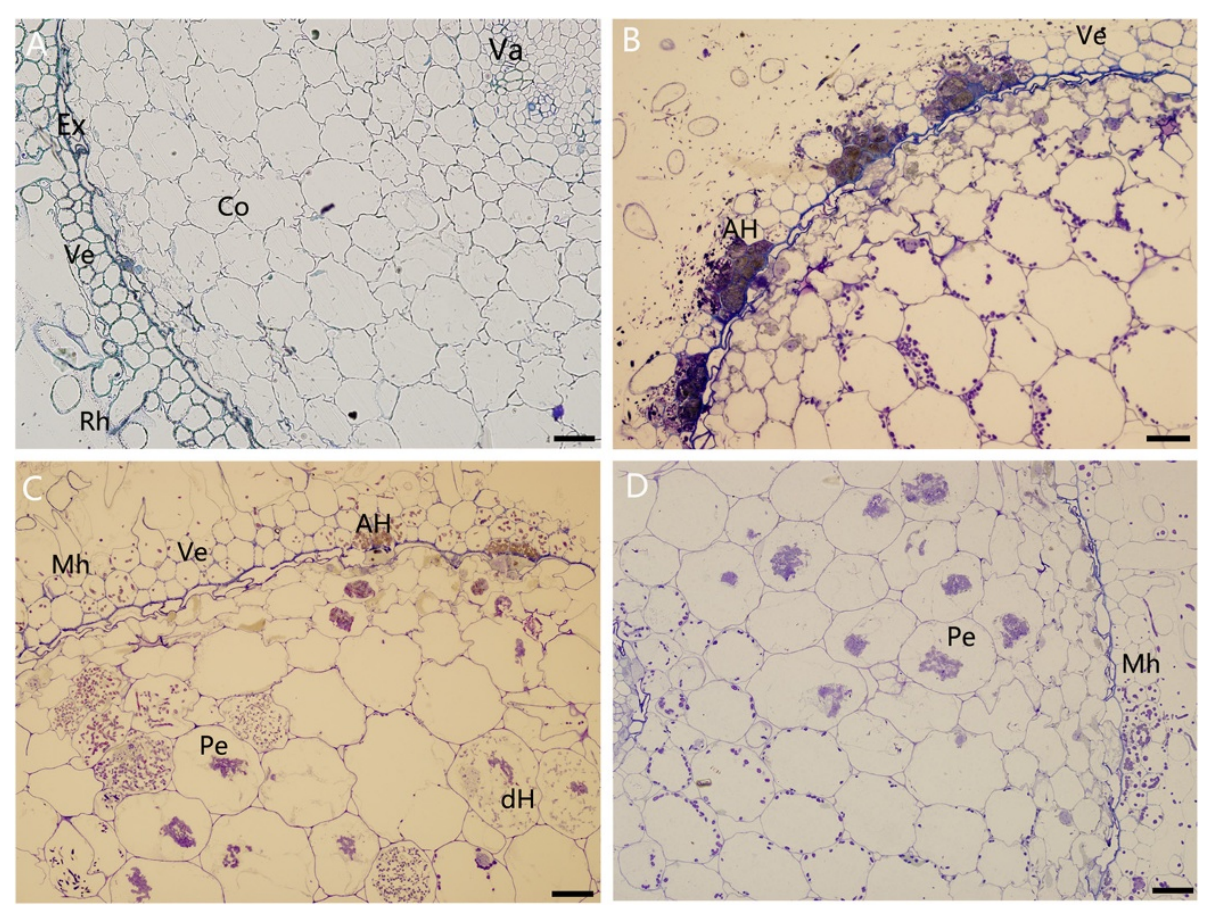

Figure 1 Microscopic structure of the symbionts formed by different $C$. hybridum- beneficial fungi interaction at 15 dpi. Mockinoculated control (A) and inoculated with isolate ZH3A-3 (B), ML01 + ZH3A-3 (C) and ML01 (D). AH, aggregated hyphae of isolate ZH3A-3; Co, cortex cells; $\mathrm{dH}$, degenerated hyphae; Ex, exodermis; Mh, fungal hyphae of isolate ML01; Pe, pelotons; Rh, root hair; Va, vascular cylinder; Ve, velamen cells. Bar, 50 um 
NCBI SRA database with the accession number SRA051368.

Three publicly available assemblers as SOAPdenovo, ABySS and Trinity were used to de novo assemble short-read RNA-seq data into transcripts. The assembly software tools as SOAPdenovo and ABySS were chosen because of their previous wide application for the similar de novo assembly of RNA-seq data sets $[31,38,39]$. Trinity method (release 20110519), one of the newest de novo assembly methods, was reported to reconstruct of the majority of full-length transcripts in a sample from RNA-seq reads directly, across a broad range of transcript levels [32]. Recent publications also showed that Trinity had a consistently better performance than the other assemblers as SOAPdenovo, ABySS, trans-ABySS, Oases with single K-mer value, when measured by transcript accuracy, integrity and completeness, and sensitivity to assemble transcripts from low to high expression levels [30]. The outcomes of three assemblers in our study were summarized in Table 2. As shown in Table 2, de novo assembly using SOAPdenovo yielded a total of 133,984 unique transcripts ( $\geq 150 \mathrm{bp}$ ), the largest number of transcripts. In contrast to the SOAPdenovo and ABySS assembly, Trinity assembled the longest mean transcript length (1127 bp), the largest N50 (1614 bp), the largest number of long-transcripts $(\geq 1 \mathrm{~kb}, 7,170$ unigenes), and the highest percentage of RMBT (40.72\%). We therefore elected to use the Trinity assembly to retain maximum information for further transcript analysis and the Trinity assembly is also available in Additional file 5.

\section{Annotation}

To validate and annotate the assembled unigenes, the 16,798 unigenes generated by Trinity were subjected to BLASTX searches (E-value $\leq 1 \mathrm{e}-5)$ against public protein databases. We found 10,915 (64.98\%), 8,486 (50.52\%), 5,720 (34.05\%) sequences with matches in NR, Swiss-Prot, and KEGG databases, respectively. In total, 10,971 (65.31\%) sequences were annotated and another 6,007 (34.69\%) unigenes showed no homology to known sequences in these databases. Among the annotated sequences, approximately
690 transcripts shared the highest similarity to fungal or bacterial sequences in NR or Swiss-Prot database. The unigenes homologous to known sequences in public databases were further annotated with GO terms using Blast2GO. A total of 3,037 (18.07\%) unigenes were assigned 6,164 GO term annotations in three categories: biological process (27.99\%), molecular function (36.32\%), and cellular component (35.69\%) (Figure 2). Metabolic process, cellular process and response to stimulus rank among the first three categories among the biological processes. The molecular functions most represented were binding, catalytic activity and transporter activity. Cell, cell part and organelle are the most represented categories in cellular components.

The global transcript abundance could be deduced from a non-normalized cDNA library. The transcripts highly abundant in the Cymbidium transcriptome are listed in Additional file 6: Table S3. There were 5,721 unigenes mapped into 119 KEGG pathways. Of the 5,721 unigenes, $1,261(22.04 \%)$ were related to metabolic pathways, 545 (9.53\%) to biosynthesis of secondary metabolites, 531 (9.28\%) to spliceosome, 439 (7.67\%) to plant-pathogen interaction, $154(2.69 \%)$ to protein processing in endoplasmic reticulum, and 109 (1.91\%) to endocytosis (Additional file 7: Table S4). From the C. hybridum transcript database, 4,871 of the assembled sequences were assigned to 10,710 COG annotations, which could be grouped into 25 categories (Figure 3). The largest category was "general function prediction only" (16.24\%), followed by "transcription" (10.92\%), "replication, recombination and repair" (9.48\%), "signal transduction mechanisms" (7.63\%), "posttranslational modification, protein turnover, chaperones" (7.18\%) and "carbohydrate transport and metabolism" (5.73\%).

\section{Validation of assembled transcripts}

To experimentally confirm that the unigenes obtained from sequencing and computational analysis were indeed expressed, 18 unigenes were chosen for further RT-PCR and Sanger-sequencing. Blastn results showed that identities of the selected reference assemblies with

Table 2 Summary of de novo sequence assembly

\begin{tabular}{|c|c|c|c|c|c|c|c|c|c|c|}
\hline \multirow[t]{2}{*}{ Software } & \multicolumn{6}{|c|}{ Length distribution of unigene (nt) } & \multirow{2}{*}{$\begin{array}{l}\text { N50 } \\
\text { (bp) }\end{array}$} & \multirow{2}{*}{$\begin{array}{c}\text { Mean } \\
\text { (bp) }\end{array}$} & \multirow{2}{*}{$\begin{array}{c}\text { All } \\
\text { unigenes } \\
\text { (nt) }\end{array}$} & \multirow{2}{*}{$\begin{array}{l}\text { Length of } \\
\text { all } \\
\text { unigenes } \\
\text { (nt) }\end{array}$} \\
\hline & $100-300$ & $300-500$ & $500-1000$ & $1000-1500$ & $1500-2000$ & $>=2000$ & & & & \\
\hline \multirow[t]{2}{*}{ Trinity } & 1,603 & 3,401 & 4,624 & 2,927 & 1,811 & 2,432 & 1614 & 1127 & 16,798 & $18,923,761$ \\
\hline & $9.55 \%$ & $20.24 \%$ & $27.53 \%$ & $17.42 \%$ & $10.78 \%$ & $14.48 \%$ & & & & \\
\hline \multirow[t]{2}{*}{ SOAPdenovo } & 87826 & 28,196 & 14,169 & 2,692 & 734 & 367 & 349 & 329 & 133,984 & $44,138,252$ \\
\hline & $65.55 \%$ & $21.04 \%$ & $10.58 \%$ & $2.01 \%$ & $0.55 \%$ & $0.27 \%$ & & & & \\
\hline \multirow[t]{2}{*}{ ABySS } & No data & 11,303 & 8,406 & 1,550 & 405 & 152 & 593 & 585 & 21,816 & $12,784,421$ \\
\hline & & $51.80 \%$ & $38.50 \%$ & $7.10 \%$ & $1.86 \%$ & $0.70 \%$ & & & & \\
\hline
\end{tabular}



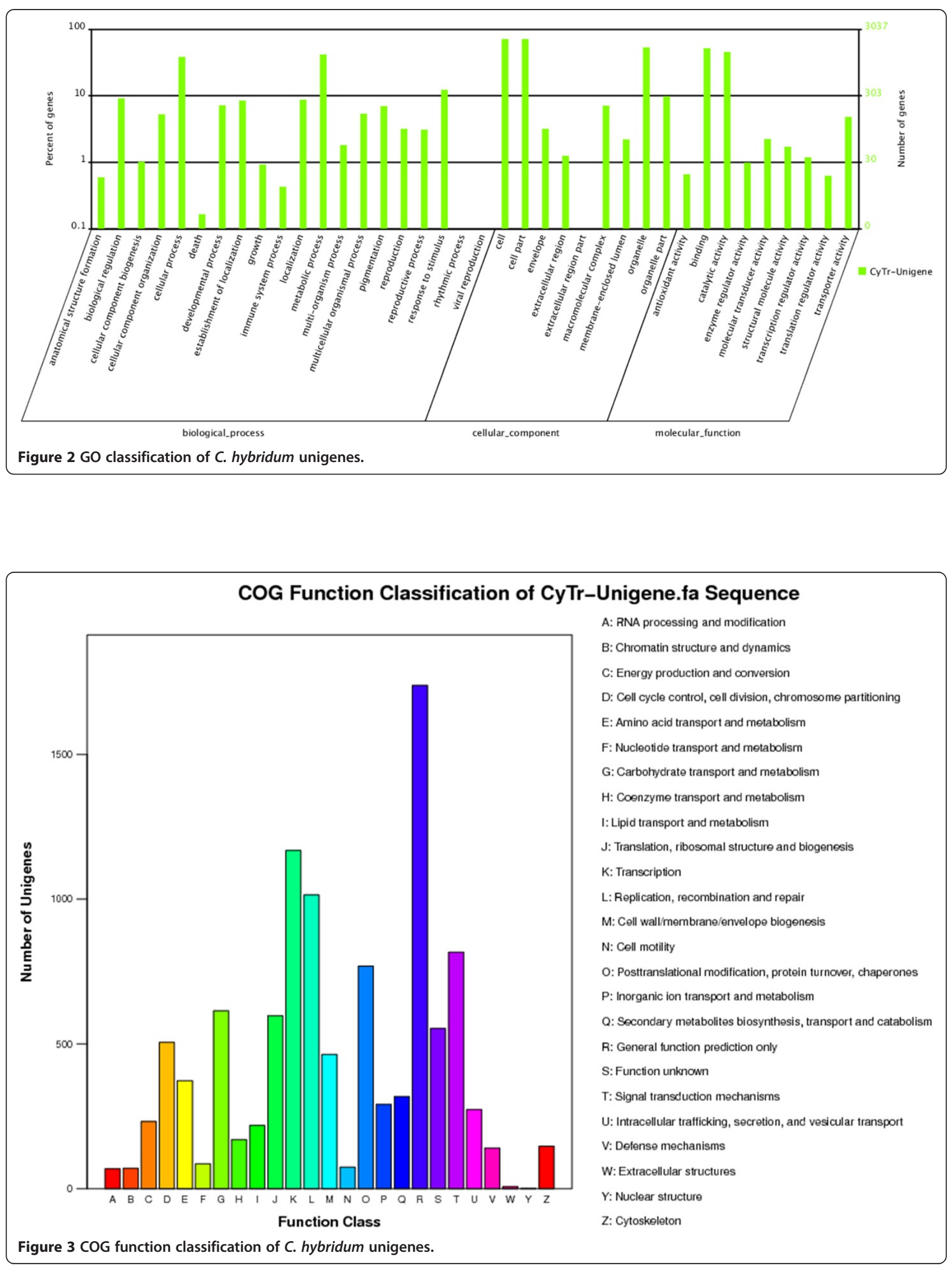
Sanger-sequencing results were between 96.02-100\% (see Additional file 1: Table S1), confirming the reliability of assembled reference transcriptome. These unigenes were also included in the next qRT-PCR analysis.

\section{Global analysis of differential gene expression in the symbiotic interaction}

Having generated a $C$. hybridum root reference transcriptome, our next goal was to perform comparative gene expression profiles in orchid roots inoculated with different beneficial fungi. A total of four independent un-normalised cDNA libraries were sequenced using the Illumina HiSeq2000 100 bp single read module (see Additional file 8: Table S5). For each library, the total number of counts for each read was determined and all the reads were mapped back to the reference transcriptome (see Additional file 9: Table S6). In this study, 10.948 million and 14.859 million reads were uniquely mapped, representing between $57.02 \%-76.41 \%$ of total reads, thus, providing good coverage for the transcript profiles.

The expression level of each assembled transcript sequence in different samples was measured through RPKM values, and the significant changes in the transcript abundance were identified applying a q-value $\leq$ 0.005 and a two-fold change threshold. Based on these criteria, at $15 \mathrm{dpi}, 1674,845$ or1743 genes were significantly regulated in $C$. hybridum root inoculated with isolates ML01, ZH3A-3 or MZ, respectively. The general differential expressed profiles in the three interactions are presented in Figure 4 and Additional file 10: Tables S7-S9. The top 100 abundant genes in symbiotic roots with positive fold change and top 100 abundant genes in non-symbiotic roots with negative fold change in response to symbiotic fungi were presented in Additional file 11: Tables S10 and S11. OM formation specifically induced $57 \%$ of the top 100 abundant genes in symbiotic roots with up-regulation pattern. Unigene2357_All (18218.59 RPKM), encoding metallothionein-like protein type 2 , which limited oxidative damage through binding to and detoxifying excess copper and other metals, was the most abundant gene in OM symbiotic roots with more than 3.6fold up-regulation. Other OM-induced genes in this category were largely involved in inhibition of reactive oxygen species (ROS) (glutathione S-transferase and superoxide dismutase $[\mathrm{Cu}-\mathrm{Zn}])$, protein metabolism and processing (ribosomal protein, histone H3.2, subtilisin-like protease, serine-type carboxypeptidase, preprotein translocase subunit SecY), signaling (calmodulinlike protein 23, lectin, adhesive/proline-rich protein), cell wall modification (extensin class, beta-mannosidase 4, beta-tubulin) and cell defense and recue (class III chitinase, ATP synthase). Twenty-three genes in this

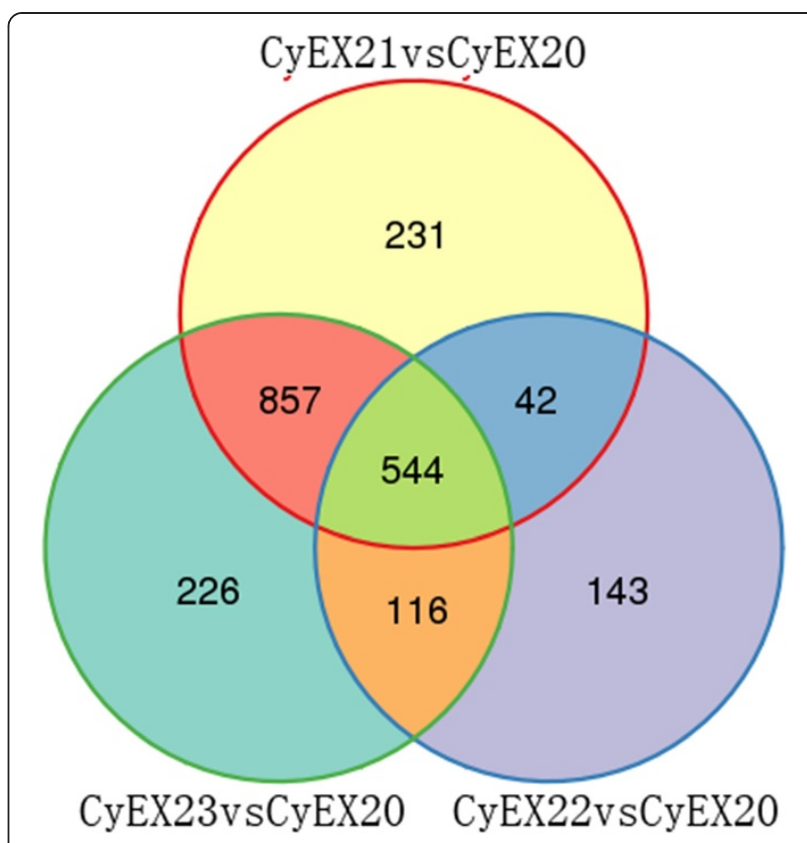

Figure 4 Venn diagram of differentially expressed genes in the $C$. hybridum- beneficial fungi interaction. Mock-inoculated (CyEX20), ML01-treated (CyEX21), ZH3A-3-treated (CyEX22) or ML01 + ZH3A3 -treated (CyEX23).

category were co-induced by three treatments, involving in signaling (cytokinin-specific binding protein 1 , annexin, calcium-binding EF hand family protein and GTPase), defense (lipoxygenase, GST, class III peroxidase, ubiquitin) and general metabolism (isoflavone reductase, alcohol dehydrogenase, enolase, lipase). However, $63 \%$ of the top 100 abundant genes in nonsymbiotic roots with negative regulation pattern in response to inoculants were shared by three treatments and another $29 \%$ of these genes were specifically down-regulated by $\mathrm{OM}$ fungi. The most representative group abundant in non-symbiotic roots and down- regulated by three treatments was attributed to genes encoding main components in photosynthesis system, whereas a mannose-specific lectin, with 49905.50 RPKM in control roots, was specifically down-regulated by OM fungi.

As shown in the Venn diagram, 544 DEGS were shared by ML01-, ZH3A-3- and MZ- treatments and 857 transcripts were collectively regulated in CyEX21 and CyEX23 but not in CyEX22 which might specifically functioned in $\mathrm{OM}$ mycorrhizal formation. Individual inoculation with non-mycorrhizal fungus ZH3A-3 specifically regulated 143 genes. Another 226 DEGS with special expression pattern in CyEX23 probably functioned in the combinative symbiotic process. All the DEGs were grouped according to hierarchical cluster analysis (Additional file 12: Figure S3) and twenty different expression sub-clusters based on k-means were 
identified (Figure 5). The lists of all the DEGs in 20 sub-clusters were also presented in Additional file 13. The genes with the same regulation pattern in three treatments were assigned to subcluster $1,3,4,5,6,7,9$, $10,11,13,15,17$ and 19 . The genes in subcluster 8,12 , 18,20 were specifically regulated by OM formation. Genes drastically up-regulated by OM fungi were included in subcluster 8, the functions of these genes were related to signaling (serine/threonine protein kinase), reactive oxygen species homeostasis and stress-related (GST, lectin, pathogenesis-related protein 10-3.2), protein metabolism and processing (ribosomal protein L10e, subtilisin, serine carboxypeptidase 1, elongation factor, amino-peptidase) and transport (ABCG, oligopeptide transporter OPT family).

GO annotation was also used to compare the functional distribution of DEGS in different treatments (Additional file 14: Figures S4-S6). Among the represented biological processes, the most represented items were "ion transport" for OM formation and "cellular biosynthetic process" for individual ZH3A-3 treatment. Among the molecular functions, most represented DEGs were categorized as "oxidoreductase activity" for $\mathrm{OM}$ formation and "cellulose synthase activity" for individual ZH3A-3 treatment. Among the cellular component, the most represented DEGS were assigned to "extracellular region" for OM formation and "plastid" for individual ZH3A-3 treatment.

To identify the biological pathways regulated during orchid- beneficial fungi interaction, we assigned the DEGs to the reference KEGG pathways (Additional file 15: Tables S12-S14). The top 20 pathways with the most representation by unique sequences for each treatment were included in Figure S7-S9 (see Additional file 16: Figures S7-S9). A large number of unigenes related to primary and secondary metabolism were collectively regulated by three treatments as 'nitrogen metabolism', 'flavonoid biosynthesis', 'cyanoamino acid metabolism', 'pentose phosphate pathway', 'starch and sucrose metabolism', 'alanine, aspartate and glutamate metabolism', 'stilbenoid, diarylheptanoid and gingerol biosynthesis', 'porphyrin and chlorophyll metabolism', 'glyoxylate and dicarboxylate metabolism', 'Metabolic pathways' and 'Biosynthesis of secondary metabolites'. Substantial numbers of genes/proteins involved in signaling pathway, protein turnover, nutrient transport, hormone action, cell rescue and defense were identified in $\mathrm{OM}$ symbiosis specifically.

\section{Validation of DEG profiling with qRT-PCR}

Using additional biological samples of ML01-, ZH3A-3and MZ- colonized roots in comparison to mockinoculated control roots, we performed real-time RT-PCR to verify the digital expression profiles of 26
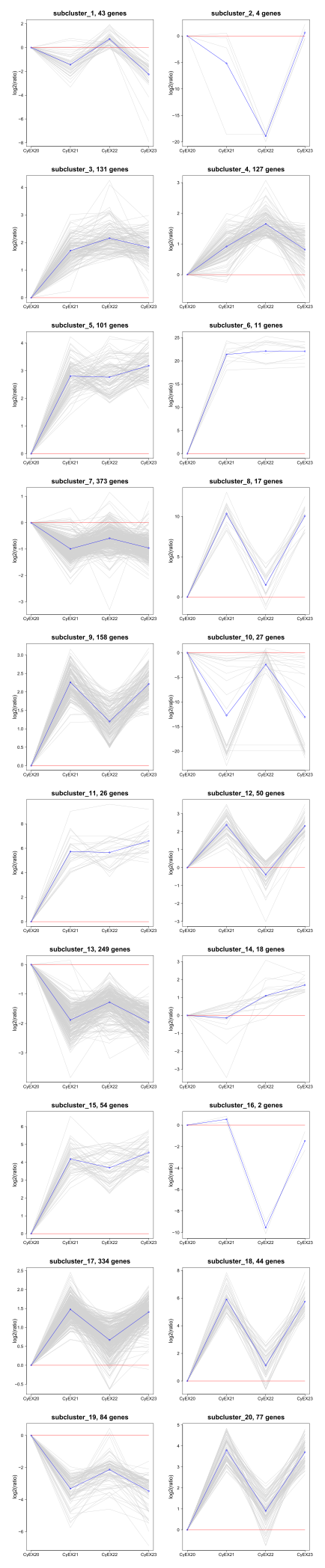

Figure 5 Twenty regulatory patterns of all the DEGs expressed in different $C$. hybridum- beneficial fungi interactions based on K-means method. 
genes corresponding to a range of functional categories and regulation patterns in the C. hybridum- beneficial fungi interactions. The Pearson correlation coefficient was calculated by SPSS to assess the correlation between different platforms. Overall, the qRT-PCR values were highly correlated with the RNA-seq results, which confirmed the general expression pattern for all the selected genes in three treatments (Table 3 and Additional file 17: Figure $\mathrm{S} 10, \mathrm{R}^{2}=0.847$, correlation was significant at the 0.01 level).

Base on the qRT-PCR results, we further analyzed the functional distribution of all the confirmed genes. The function of co-regulated genes in three treatments included signaling (CBL-interacting serine/threonineprotein kinase 11), membrane proliferation (cellulose synthase A catalytic subunit 4), scavenging of reactive oxygen species (glutathione peroxidase), general stressresponsive (laccase-4-like), nutrient transport (inorganic phosphate transporter, major facilitator family protein, oligopeptide transporter 1-like), protein processing (xylem serine proteinase 1 precursor), transcription factor (ethylene-responsive element binding factor 4, NAC domain-containing protein 43-like, zinc finger $\mathrm{CCCH}$ domain-containing protein 66-like) and hormone transport (auxin efflux facilitator PIN1). DEGs derived exclusively from OM roots were assigned to signaling (LysM domain receptor-like kinase 3-like), transport (equilibrative nucleoside transporter, ATPase 7, plasma membrane-type-like, peptide transporter PTR3-A-like), transcription factor (Unigene 2569_All), cell defense (chitinase 4-like) and hormone metabolism (gibberellin 20-oxidase). Two genes showed special expression pattern in response to $\mathrm{ZH} 3 \mathrm{~A}-3$ treatment, including Unigene 4239_All (putative boron transporter 2) and Unigene 13219_All (putative trans-membrane copper transporter).

\section{Discussion}

Some different effects of mycorrhizal and nonmycorrhizal fungi on the growth of $C$. hybridum plantlets This study demonstrated that the vegetative growth of C. hybridum plantlets could be improved by orchid mycorrhizal fungus ML01 and/or non-mycorrhizal isolate $\mathrm{ZH} 3 \mathrm{~A}-3$. It is widely accepted that Tulasnellalike Rhizoctonia formed typical mycorrhizae with orchids and improved their germination and their seedlings' growth [40,41]. Consistent with these studies, ML01 formed typical pelotons in host root cortex and significantly improved the total fresh weight (FW) and dry biomass (DW) of C. hybridum plantlets compared to the control. However, we observed that the roots of ML01- treated plantlets did not elongate obviously as the co-cultivation proceeded, which might be due to rapid acidification of the co-cultivation media (our unpublished data). It was thus inferred ML01 increased the total dry biomass of orchid plantlets through improving the absorption of mineral nutrient. Non-mycorrhizal fungus ZH3A-3 alone showed similar promoting effects on total FW and DW of Cymbidium plantlets to that of MZ treatment at 45 dpi (Table 1), but we also observed that individual ZH3A-3- treated orchids initiated less new roots than that of dual- inoculated plantlets, and their leaves turned into light green after a prolonged cocultivation. Isolate $\mathrm{ZH} 3 \mathrm{~A}-3$ always co-existed with Tulasnella-like Rhizoctonia in wild orchid roots and the hyphae of isolate $\mathrm{ZH} 3 \mathrm{~A}-3$ mainly spread in velamen cells and could not form pelotons in the cortex cells of Cymbidium roots. It was also revealed that the effects of isolate ZH3A-3 and another OMF isolate (CLO1) on hosts' uptake of mineral nutrient were complementary in our recent report [8]. Thus, we designated ZH3A-3 as mycorrhizal-associated fungi.

\section{Functional analyses of differentially regulated genes by OM symbiosis}

The establishment of OM symbiosis involves the mutual recognition of host and fungi, hypha penetrating the cell walls of root hairs or epidermis and then entering the cells of the cortical parenchma, forming characteristic and complex hyphal coils (pelotons) [2]. As in other endomycorrhizal systems, the plant cell membranes in the infected tissues remain intact at all times, excluding the hyphae from the cytoplasmic compartment, and an interfacial matrix is formed between the invading hyphae and the invaginating plant plasmalemma [5]. The fungi further spread either as a result of repeated colonization or by hyphae penetrating from cell to cell in the root cortex, and the cortex cells may be uncolonized or contain active pelotons or clumps of degenerating hyphae in different proportions. So, Rasmussen et al. [5] proposed that there co-existed necrotrophic and biotrophic phase in orchid mycorrhiza, and the former referred to peloton degradation and unilateral nutrient transfer by endocytosis, and the latter, mutual nutritional exchange [5]. A recent labeling study in Spiranthes sinensis clearly indicated that in the symbiotic protocorm, hyphal degeneration played a significant role in the mass transfer of the elements to plant cells, and fungal carbon and nitrogen was also detected to be transferred from live hyphae through the interface between the symbionts [42]. Owing to the non- synchronous process, the symbiotic root system often contains fungal structures in different developmental stages (contact, penetrating hyphae, intracellular hyphae, active and degenerating pelotons), and the functions of DEGs for OM symbiosis were widely distributed. 
Table 3 Comparison of the expression profiles of 26 genes by RNA-seq and quantitative real-time RT-PCR

\begin{tabular}{|c|c|c|c|c|c|c|c|}
\hline \multirow[t]{2}{*}{ Gene ID } & \multirow[t]{2}{*}{ Annotation } & \multicolumn{2}{|c|}{$M / C K$ ( $\log _{2}$ fold) } & \multicolumn{2}{|c|}{$\mathrm{Z} / \mathrm{CK}$ ( $\log _{2}$ fold) } & \multicolumn{2}{|c|}{$\mathrm{MZ} / \mathrm{CK}\left(\log _{2}\right.$ fold $)$} \\
\hline & & $\begin{array}{l}\text { RNA- } \\
\text { seq }\end{array}$ & $\begin{array}{l}\text { qRT- } \\
\text { PCR }\end{array}$ & $\begin{array}{l}\text { RNA- } \\
\text { seq }\end{array}$ & $\begin{array}{l}\text { qRT- } \\
\text { PCR }\end{array}$ & $\begin{array}{l}\text { RNA- } \\
\text { seq }\end{array}$ & $\begin{array}{l}\text { qRT- } \\
\text { PCR }\end{array}$ \\
\hline Unigene 1724_All & ethylene receptor homolog2 & 1.72 & $1.59 \pm 0.24$ & 1.19 & $0.73 \pm 0.09$ & 1.87 & $1.51 \pm 0.05$ \\
\hline Unigene 1869_All & LysM domain receptor-like kinase 3-like & 4.26 & $4.29 \pm 0.06$ & 0.51 & $0.98 \pm 0.19$ & 3.97 & $3.85 \pm 0.03$ \\
\hline Unigene 2625_All & calmodulin binding protein, putative & 1.19 & $0.95 \pm 0.16$ & 0.87 & $0.38 \pm 0.15$ & 1.30 & $0.64 \pm 0.10$ \\
\hline Unigene 4130_All & sugar transporter ERD6-like 7-like & 1.74 & $1.70 \pm 0.21$ & 0.84 & $1.01 \pm 0.05$ & 2.03 & $1.63 \pm 0.38$ \\
\hline Unigene 4239_All & boron transporter 2 & 0.96 & $0.58 \pm 0.25$ & -2.17 & $\begin{array}{c}-3.07 \pm \\
0.06\end{array}$ & 0.61 & $0.27 \pm 0.39$ \\
\hline Unigene 6086_All & inorganic phosphate transporter, putative & 3.01 & $2.81 \pm 0.34$ & 2.49 & $2.90 \pm 0.26$ & 3.40 & $3.06 \pm 0.10$ \\
\hline Unigene 8895_All & Xyloglucan endotransglucosylase/hydrolase & 2.03 & $0.58 \pm 0.66$ & 2.55 & $1.74 \pm 0.49$ & 1.89 & $\begin{array}{c}-0.07 \pm \\
0.38\end{array}$ \\
\hline $\begin{array}{l}\text { Unigene } \\
\text { 10786_All }\end{array}$ & equilibrative nucleoside transporter & 3.95 & $4.71 \pm 0.11$ & -0.21 & $0.42 \pm 0.08$ & 3.94 & $4.41 \pm 0.05$ \\
\hline $\begin{array}{l}\text { Unigene } \\
\text { 12197_All }\end{array}$ & ethylene-responsive element binding factor 4 & 2.33 & $1.83 \pm 0.53$ & 3.12 & $2.72 \pm 0.39$ & 3.37 & $2.74 \pm 0.11$ \\
\hline $\begin{array}{l}\text { Unigene } \\
\text { 13078_All }\end{array}$ & glutathione peroxidase & 4.20 & $2.62 \pm 0.15$ & 1.67 & $1.04 \pm 0.27$ & 3.95 & $2.45 \pm 0.06$ \\
\hline $\begin{array}{l}\text { Unigene } \\
\text { 13219_All }\end{array}$ & transmembrane copper transporter & -6.93 & $\begin{array}{c}-1.01 \pm \\
0.03\end{array}$ & 8.05 & $8.15 \pm 0.44$ & 6.51 & $4.65 \pm 0.06$ \\
\hline $\begin{array}{l}\text { Unigene } \\
\text { 13639_All }\end{array}$ & ATPase 7, plasma membrane-type-like & 4.24 & $4.39 \pm 0.09$ & 0.52 & $0.32 \pm 0.11$ & 3.94 & $3.81 \pm 0.09$ \\
\hline $\begin{array}{l}\text { Unigene } \\
\text { 14415_All }\end{array}$ & major facilitator family protein & -2.13 & $\begin{array}{c}-1.55 \pm \\
0.50\end{array}$ & -0.97 & $\begin{array}{c}-1.13 \pm \\
0.86\end{array}$ & -2.36 & $\begin{array}{c}-1.91 \pm \\
0.50\end{array}$ \\
\hline $\begin{array}{l}\text { Unigene } \\
\text { 15955_All }\end{array}$ & sorbitol transporter & 2.32 & $2.86 \pm 0.38$ & 0.87 & $1.54 \pm 0.21$ & 2.27 & $2.20 \pm 0.07$ \\
\hline $\begin{array}{l}\text { Unigene } \\
\text { 13573_All }\end{array}$ & $\begin{array}{l}\text { cellulose synthase A catalytic subunit } 4 \text { [UDP-forming]- } \\
\text { like }\end{array}$ & 4.76 & $7.26 \pm 0.91$ & 4.94 & $7.61 \pm 0.87$ & 4.67 & $6.50 \pm 0.89$ \\
\hline Unigene 2569_All & transcription factor, putative & 2.18 & $2.68 \pm 0.30$ & 0.00 & $0.38 \pm 0.20$ & 2.00 & $2.41 \pm 0.32$ \\
\hline $\begin{array}{l}\text { Unigene } \\
\text { 14999_All }\end{array}$ & NAC domain-containing protein 43 -like & 4.19 & $3.73 \pm 0.36$ & 4.60 & $4.53 \pm 0.32$ & 4.32 & $3.09 \pm 0.18$ \\
\hline $\begin{array}{l}\text { Unigene } \\
\text { 16297_All }\end{array}$ & CBL-interacting serine/threonine-protein kinase 11 & 1.80 & $1.34 \pm 0.35$ & 1.61 & $1.80 \pm 0.18$ & 2.17 & $1.55 \pm 0.35$ \\
\hline $\begin{array}{l}\text { Unigene } \\
\text { 10727_All }\end{array}$ & zinc finger $\mathrm{CCCH}$ domain-containing protein 66-like & 2.22 & $2.07 \pm 0.24$ & 3.09 & $2.82 \pm 0.04$ & 3.53 & $2.87 \pm 0.01$ \\
\hline $\begin{array}{l}\text { Unigene } \\
\text { 15958_All }\end{array}$ & chitinase 4-like & 20.38 & $13.75 \pm 0.15$ & 0.00 & $\begin{array}{c}-0.04 \pm \\
0.34\end{array}$ & 20.09 & $13.40 \pm 0.21$ \\
\hline Unigene 4429_All & laccase-4-like & 2.35 & $2.35 \pm 0.29$ & 2.81 & $3.38 \pm 0.06$ & 1.96 & $1.81 \pm 0.19$ \\
\hline $\begin{array}{l}\text { Unigene } \\
\text { 11039_All }\end{array}$ & auxin efflux facilitator PIN1 & 3.42 & $3.27 \pm 0.39$ & 3.74 & $2.84 \pm 0.07$ & 3.77 & $3.00 \pm 0.25$ \\
\hline $\begin{array}{l}\text { Unigene } \\
\text { 15779_All }\end{array}$ & Xylem serine proteinase 1 precursor, putative & 1.54 & $2.09 \pm 0.30$ & 2.40 & $3.21 \pm 0.13$ & 1.79 & $2.32 \pm 0.20$ \\
\hline Unigene 2376_All & peptide transporter PTR3-A-like & 2.92 & $2.38 \pm 0.37$ & -1.01 & $\begin{array}{c}-1.44 \pm \\
0.45\end{array}$ & 2.79 & $1.70 \pm 0.14$ \\
\hline Unigene 2386_All & oligopeptide transporter 1-like & 4.51 & $4.90 \pm 0.49$ & 1.66 & $2.51 \pm 0.46$ & 4.57 & $4.86 \pm 0.49$ \\
\hline $\begin{array}{l}\text { Unigene } \\
\text { 13170_All }\end{array}$ & gibberellin 20-oxidase & 1.66 & $2.13 \pm 0.05$ & 0.03 & $0.45 \pm 0.16$ & 1.14 & $1.00 \pm 0.27$ \\
\hline
\end{tabular}

Fold changes of selected C. hybridum trasncripts ( \pm standard deviation) were logarithmic transformed which were determined by RNA-seq and qRT-PCR in root tissues treated with isolates ML01 (M), ZH3A-3 (Z) and ML01+ ZH3A-3 (MZ) at 15 dpi as compared to mock-inoculated control (CK).

Genes related to signaling pathway

LysM-domain containing receptor-like kinases (LysM-RLK) were identified as receptors of acylated chitin (Nod factors) or chitin produced by plant interacting microbes and confirmed to be involved in signaling during nodule and AM development $[13,43,44]$. In this context, it is noteworthy 
that two genes (Unigene8696_All, Unigene 1869_All) predicted to encode LysM domain receptor-like kinases showed evident up-regulation in OM symbiosis. One of them, Unigene 1869_All, encodes a protein with 56\% identity to LysM type receptor kinase LYS3 from $L$. japonicus (BAI79284). Its induction was validated by qRT-PCR, which measured 16-fold up-regulation in the mycorrhizal roots. This was consistent with the notion that symbiosis signaling seems to occur throughout the process of root colonization by a symbiont and occurs in parallel to additional signaling mechanisms that require the LysM receptor-like kinases [45].

$\mathrm{Ca}^{2+}$ spiking in the nucleus and perinuclear region of root hair cells has been documented as one of the earliest cellular responses after the perception of symbionts by host plants [46]. Our digital analysis also revealed many transcripts associated with $\mathrm{Ca}^{2+}$ signals, as annexin and calcium-binding EF hand family proteins were coregulated by three treatments. But we also detected some transcripts in this group were specifically regulated by $\mathrm{OM}$ fungi, including five genes encoding calcium-binding proteins (Unigene4048_All, Unigene6332_All, Unigene11025_All, Unigene3685_All, Unigene3072_All), two genes encoding homologues of calcium-dependent protein kinase (CDPK) (Unigene6383_All, Unigene8933_All), one cyclic nucleotidegated ion channel protein (Unigene5311_All), and one gene (Unigene6051_All), encoding a homologue of DMI2 nodulation receptor kinase from $M$. truncatula.

Another interesting finding was that two transcripts (Unigene10121_All and Unigene456_All, up-regulated more than 2-fold) encoding putative GRAS family protein with equal $44 \%$ identity to LjNSP1 (nodulationsignaling pathway 1 protein) from $L$. japonicas, and one gene (Unigene7236_All, down-regulated more than 2 -fold), which encoded GRAS family transcription factor with 56\% identity to NSP2 (nodulation-signaling pathway 2 protein) from $M$. truncatula, were also specifically regulated by OM symbiosis. NSP1 and NSP2 are required for rhizobium-specific gene expression whereas only NSP2 might be required for mycorrhizal signaling and NSP1 is replaced with required for arbuscular mycorrhization 1 (RAM1) to drive expression of mycorrhiza-specific genes [45].

\section{Genes involved in cellular organization and protein processing}

A substantial number of genes related to cell wall modification were found to be co-regulated in three treatments, which encoded probable xyloglucan endotransglucosylase, beta-D-xylosidase or cellulose synthase. Two of these were confirmed by qRT-PCR. Unigene 8895_All, encoding a protein with $75 \%$ identity to the xyloglucan endotransglucosylase (XET) of Medicago trancatula, was co-induced more than 4-fold. Another gene (Unigene 13573_All) was strongly up-regulated more than 32-fold upon symbiosis (Table 3). The translated protein shares $92 \%$ identity to cellulose synthase A (CesA) catalytic subunit of Vitis vinifera. CesA proteins are part of the cellulose synthase complex in higher plants located in the plasma membrane [47]. Guether et al. [11] also confirmed that two transcripts of Lotus, LjCel1 and LjCesA, accumulated specifically in the arbusculated cells and functioned in cell expansion during arbuscule development [11]. The strongly up-regulated transcripts of putative cellulose synthase might be involved in plant cell wall reinforcement during fungal colonization.

Similar to AM fungi, orchid mycorrhizal fungi penetrate the plant cell wall but not the plasma membrane. As the colonization proceeds, the host plasma membrane invaginates and the infected cells often contain numerous mitochondria, ribosomes and profusely developed ER. A large number of sequences that were specifically induced by OM formation were assigned to protein metabolism and turnover, membrane dynamics and cell wall synthesis. This group of OM specifically induced genes in Cymbidium were thought to be homologues associated with AM and ectomycorrhizal symbioses [11].

Besides the co-regulated DEGS among three treatments, OM symbiosis also specifically induced a high number of transcripts encoding cell wall-degrading enzymes, including five glucan endo-1,3-beta-glucosidase, one pectinesterase 3 and one xyloglucan endotransglucosylase/hydrolase protein. Concomitantly, three extensin- like proteins (Unigene11713_All, Unigene13380_All, Unigene16702_All), and three putative glycosyltransferases (Unigene12916_All, up-regulated more than 300-fold; Unigene12916_All and Unigene9981_All, up-regulated more than 4-fold) involved in cell wall reinforcement were also found in our dataset. Overall, this indicates an importance of wall- strength maintenance in $\mathrm{OM}$ symbiosis. With regard to membrane proliferation, two homologues of $A$. thaliana syntaxin SYP 132, Unigene10103_All and Unigene7281_All, were exclusively induced 16- and 6- fold by mycorrhizal symbiosis. Syntaxin belong to the superfamily of the SNARE proteins that play key roles in membrane fusion events during vesicle trafficking. In AM symbiosis, a gene (Ljwgs_016013.1) encoding a protein with a 60\% identity to the $A$. thaliana syntaxin SYP 132 also showed seven-fold up-regulation and was suggested to facilitate plant/fungal compatibility in mycorrhizal Lotus roots [11].

Protein metabolism and processing seems to be a major process in mycorrhizal symbiosis $[11,48,49]$. Most drastically up OM- regulated genes in the present study were involved in protein synthesis and processing (Additional file 11: Tables S10 and S11). Concerning protein synthesis, the strong induction of different ribosomal proteins in response to OM fungi provided evidence. A number of transcripts associated with protein 
turnover were also detected in our analysis, including three subtilisin-like proteases (Unigene7254_All and Unigene16547_All, up-regulated more than 1000-fold; Unigene10817_All, up-regulated more than 2000-fold), three serine carboxypeptidase (Unigene4706_All, upregulated more than 1500- fold; Unigene12600_All, up-regulated more than 300-fold; Unigene5600_All, up-regulated more than 6-fold), and also some peptidase (Unigene15372_All, up-regulated more than 320 fold; Unigene2916_All, up-regulated more than 40-fold; Unigene11542_All, up-regulated more than 4-fold). Some transcripts associated with correct protein folding (Unigene4797_All, Unigene7897_All) and degradation of mis-folded protein (Unigene11189_All, Unigene11236_All, Unigene15698_All, Unigene7179_All, Unigene 6288_All) were also identified as specifically up-regulated in OM symbiosis. At the same time, a transcript of putative serine-type endopeptidase inhibitor, Unigene16319_All, accumulated more than 40-fold in the mycorrhizal roots compared with controls, which might fine-tune protein processing.

\section{Transport-related genes}

Phosphate transfer to the adult orchids via mycorrhizal fungi was well documented, just as in other mycorrhizal systems. Recently, labeling experiments also directly demonstrated that the fully autotrophic orchid Goodyera repens acquires carbon, nitrogen and phosphorous from its fungal partner $[9,10,50]$. Notably, G. repens also transfers significant amounts of photosynthate (likely greater than $3 \%$ of its photosynthetic carbon) back to its Ceratobasidium mycobiont - the first direct demonstration of a net carbon flow from orchid to fungus $[9,10]$. Tulasnella-like Rhizoctonia were also confirmed to improve the plant growth of $C$. spp. by enhancing nutrient acquisition [8].

In our global profiling analysis, 15 genes associated with membrane transport were identified as co-regulated in three treatments. Among them, 7 genes involved in nutrient transport were co-induced in symbiotic roots, including two inorganic phosphate transporters (Unigene6086_All, Unigene6124_All), a plasma membrane ATPase 4 (Unigene6958_All), a BCS1 protein precursorlike (AAA ATPase chaperone, Unigene14840_All) a sorbitol transporter (Unigene15955_All), an oligopeptide transporter 1-like (Unigene2386_All) and a magnesium transporter (Unigene11188_All), whereas 8 genes were co-repressed at this time point which encoded two putative copper-transporting ATPase, a copper transporter, a probable nitrite transporter, a sulfate transporter 3.1, an inorganic phosphate transporter $2-1$, chloroplastic, a probable sodium-coupled neutral amino acid transporter 6 and a member of major facilitator family. Of these, the expression pattern of five genes was further verified by
qRT-PCR. The first of these, Unigene6086_All, was coinduced more than 5-fold, which encodes an inorganic phosphate transporter with $81 \%$ similarity to inorganic phosphate transporter 1-4 of Arabidopsis thaliana and a shared $78 \%$ identity to inorganic phosphate transporter from Lotus japonicus (LjPT3, LjPT4) and M. truncatula (MtPT6). Both deduced amino acid sequences of two up-regulated inorganic phosphate transporter genes (Unigene6086_All, Unigene6124_All) in our digital profiling have similarity to reported mycorrhiza-specific or -induced phosphate transporters [51] (Figure 6). The second gene, Unigene2386_All, which was up-regulated between 4- and 16- fold in the symbiotic process, encodes a protein with $63 \%$ identity to $V$. vinifera oligopeptide transporter 1-like. Another two co-induced genes (Unigene15955_All, Unigene4130_All) were involved in carbohydrate transmembrane transport and further identified by qRT-PCR (Table 3). Unigene15955_All encodes a putative sorbitol transporter with $71 \%$ similarity to sorbitol transporter of Zea mays and Unigene4130_All encodes a transporter with $60 \%$ identity to sugar transporter ERD6-like 7 of $A$. thaliana. Finally, a member of a major facilitator family (Unigene14415_All) was confirmed to be repressed more than 4-fold in symbiotic roots and its translated sequence shared $68 \%$ similarity to a major facilitator family protein of $A$. thaliana. In general, the regulation of a number of transporter genes supported the notion that extensive nutrient exchange was involved in symbiosis of the host and beneficial fungi.

We also identified a substantial proportion of genes involved in transport which were specifically regulated in mycorrhizal roots. These included three transcripts (Unigene11510_All, up-regulated 100 fold; Unigene13639_All, up-regulated 15 fold; Unigene2212_All, up-regulated 32 fold) encoding putative plant plasma membrane proton ATPases. The amino acid sequence of the encoded protein by Unigene11510_All shares 77\% identity with the AMspecific Mtha1in M. truncatula. The regulation of another transcript (Unigene13639_All) was validated by qRT-PCR (Table 3) and its translated sequence shared $70 \%$ similarity to $\mathrm{H}^{+}$-ATPase 7 from A. thaliana. In $\mathrm{OM}$, like in $\mathrm{AM}$ and $\mathrm{ECM}$, nutrients from symbiotic hyphae separated at the apoplastic space have to go through several membrane barriers before being assimilated by the partner's cells, so the activated plant plasma membrane proton ATPase might be a sign of accelerated membrane transport. The other two genes (Unigene13137_All, up-regulated 7 fold; Unigene3152_All, up-regulated 2 fold) were also identified as OM-specific which encoded a putative copper-exporting ATPase and a plasma membrane calcium-transporting ATPase, respectively.

Another group of mycorrhizal-induced genes identified was associated with nitrogen transport. Eight genes of 


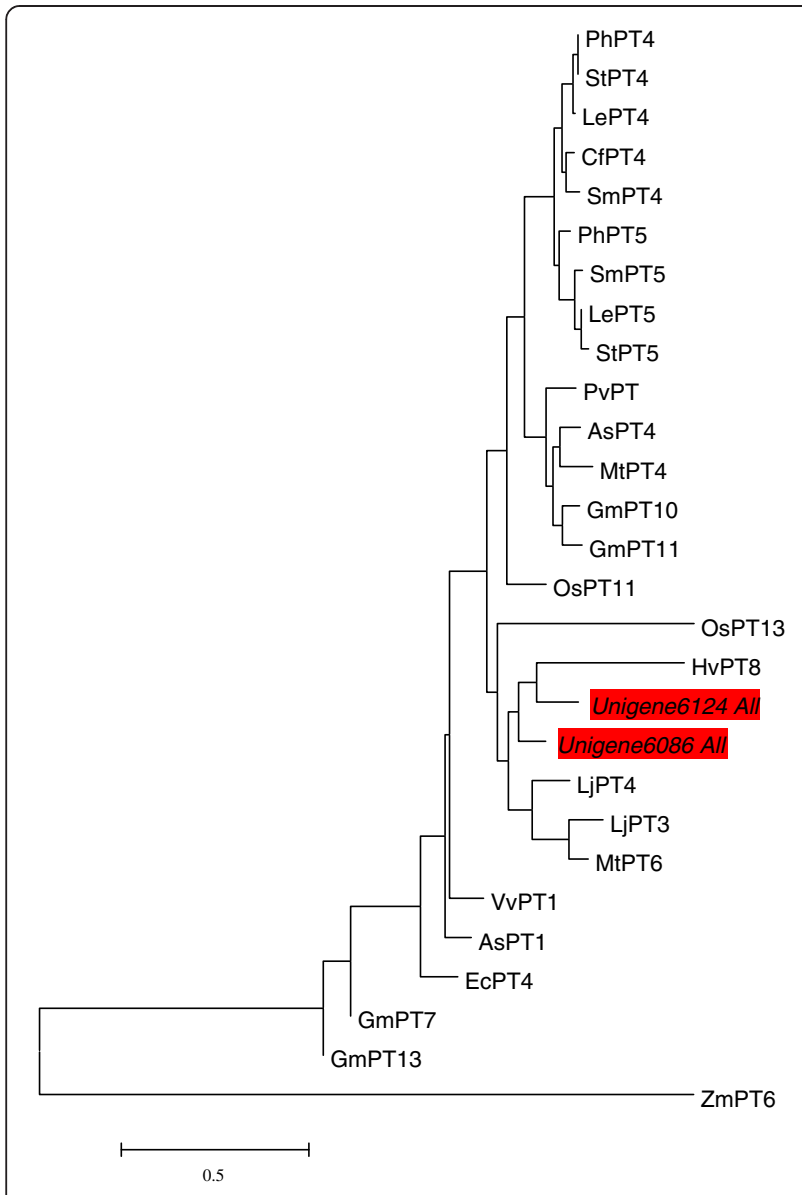

Figure 6 Phylogenetic tree for the amino acid sequences of plant phosphate transporters (PiTs) described as mycorrhizaspecific or -induced transporters, and two putative PiTs of $C$. hybridum (Unigene6086_All, Unigene6124_All) in this study were highlighted in red color. The dendrogram was generated by Mega 4.0 software using ClustlW for the alignment and the neighbor-joining method for the construction of phylogeny. The plant Pi-transporters accession numbers could be obtained in [49].

peptide transporter (PTR) were found to be exclusively up-regulated between two-fold and more than 300-fold compared with controls. The strongest up-regulated PTR (Unigene4918_All), encoding a homologue of peptide transporter PTR1 of $M$. truncatula with $62 \%$ identity, showed none expression level in the control and CyEX22 samples. The second putative PTR (Unigene8412_All) was 300-fold up regulated in mycorrhizal roots at $15 \mathrm{dpi}$ and had a $76 \%$ similarity to a member of oligopeptide transporter family (OPT) from $P$. trichocarpa. Quantitative RT-PCR analysis confirmed that one transcript (Unigene2376_All) was upregulated more than 7-fold in OM symbiosis whereas down regulated two-fold in ZH3A-3-treated orchid roots. Besides these PTRS, two putative amino acid transporters were also detected to be induced by mycorrhizal formation. A homology search revealed $70 \%$ identity between the translated amino acid sequence of Unigene3142_All and cationic amino acid transporter 5 (CAT5) of $A$. thaliana. The second gene, Unigene404_All, encodes a protein with $81 \%$ identity to LHT1 (lysine histidine transporter 1) of A. thaliana (thale cress), which was regulated by diverse factors. Our data supported the notion that OMF played an important role in improving $\mathrm{N}$ acquisition of host plants [9,27].

Two putative monosaccharide transporter genes (Unigene12841_All, Unigene4472_All) were also found to be induced in OM mycorrhizal roots. The closest homologue of translated sequence by Unigene12841_All in A. thaliana is sugar-proton symporter PLT5 (AtPLT5), with $71 \%$ identity at amino acid level. Another gene, Unigene4472_All, encoded a homologue with 70\% similarity to a tonoplast monosaccharide transporter 2 (TMT2) in A. thaliana and TMT1/2 probably represents a family of proton-coupled antiporters capable of high-capacity loading of glucose and sucrose into the vacuole. Gaude et al. [48] also demonstrated that two putative sucrose transporters and one hexose transporter were induced in noncolonized cortical cells of mycorrhizal roots compared to the cortical cells of non-mycorrhizal roots, and suggested they might be involved in the uptake of carbohydrate from the apoplast into cells in the vicinity of hyphae in arbuscular mycorrhizal roots or functioned in the proton-coupled uptake of carbohydrate into the cytoplasm from the vacuole [48]. This raises a compelling question of what is the exact function of these two putative monosaccharide transporters in our study. Finally, a gene encoding a putative potassium transporter (Unigene14628_All) was also detected to be 6-fold upregulated in mycorrhizal roots and shared $50 \%$ identity at the amino acid level with the potassium transporter 1 of A. thaliana.

In addition to a number of up-regulated genes probably involved in nutrient transport, ATP binding cassette (ABC) transporter genes, which are unlikely associated with direct nutrient transport, were also identified to be regulated in mycorrhizal roots. The strongest up-regulated gene of ABC transporter family (Unigene5835_All, up-regulated nearly 1,000 -fold) encoded a protein with $66 \%$ identity to PDR3 ABC transporter of Oryza sativa, which was regulated by many abiotic and biotic factors. Recently, two plant half-size ATP binding cassette $(\mathrm{ABC})$ transporter proteins (STR/STR2) were identified that are essential for $\mathrm{AM}$ symbiosis [52] and one full-size $\mathrm{ABC}$ transporter gene MtABCB1 (Medtr8g025810) showed strongly increased transcript levels in arbuscule-containing (ARB) cells and also in adjacent cells [48]. These ABC transporter proteins may be involved in the transport of signaling between plant cells during AM symbiosis [48]. Here, these identified ABC transporter genes showing different expression patterns in orchid mycorrhizal roots may be important for $\mathrm{OM}$ symbiosis. 
OM-activated transcripts also included components associated with vesicle-mediated transport, which might involve in the membrane biogenesis for an intracellular accommodation of fungal structures. The translated sequence of Unigene7513_All (up-regulated more than 3-fold) shares 70\% identity with VAMP7B (vesicle- associated membrane protein $7 \mathrm{~B}$ ) in A. lyrata subsp. lyrata. Another gene, Unigene11358_All, encoding a putative clathrin assembly protein, was up-regulated more than 8 -fold in mycorrhizal roots.

\section{Defense -related and phytohormone regulation}

Oxidative burst belongs to early events of plant responses to compatible and incompatible fungi. The success of beneficial microbes to colonize plant roots depends on their ability to manipulate immune responses of the host. This was verified by the findings of transcripts associated with scavenging of reactive oxygen species (ROS), such as glutathione peroxidase, probable glutathione S-transferase (GSTF1) and germin-like protein (Unigene6491_All, up-regulated more than 37-fold; Unigene5007_All, up-regulated more than 25-fold; Unigene4304_All, up-regulated more than 4-fold), accumulating in the symbiotic roots. One of these, Unigene13078_All, encodes a protein with $77 \%$ identity to the glutathione peroxidase of Populus trichocarpa and was further validated by qRT-PCR.

Concomitantly, many transcripts encoding general 'stress- responsive' proteins (e.g. laccase-4-like; probable pectinesterase/pectinesterase inhibitor 34 (Unigene11474_All); bibenzyl synthase (Unigene1160_All, Unigene1836_All, Unigene4746_All) were identified to be induced in these symbiotic process. The enzymes in the pathway towards fungicidal phytoalexin synthesis are produced as a general feature in orchids. Reinecke [53] have reported that the activity of benzyl synthase, catalyzing the biosynthesis of bibenzyls and 9, 10-dihydrophenanthrenes of Bletilla striata rhizomes, increased substantially upon fungal infection [53]. Another interesting finding was that two transcripts encoding programmed cell death protein 4 (PDCD4, Unigene3283_All and Unigene14957_All) were down regulated collectively in three treatments. PDCD4, a suppressor of gene transcription and translation, plays a crucial inhibitory role in several types of human tumors through inhibiting autophagy in multiple cell types both in vitro and in vivo [54]. Downregulation of these homologues of PDCD4 may promote the symbiotic process through suppressing plant defense. Furthermore, four transcripts (Unigene4420_All, Unigene8976_All, Unigene8566_All, Unigene13020_All), encoding homologues to key molecular regulators in two-component systems (TCSs) which play important roles in responses to environmental stress stimuli [55], were found to be down regulated regardless of the inoculated fungi species, highlighting the shared strategy by different beneficial fungi in the symbiosis.

Apart from these shared DEGs, three chitinase genes (Unigene15958_All, Unigene16629_All, Unigene8905_All) were exclusively induced by OM fungi and the specific expression pattern of Unigene 15958_All was confirmed by qRT-PCR. The translated sequence of Unigene 15958_All shared 59\% identity with the chitinase 4-like of Fragaria vesca. Chitinases hydrolyze $\beta$-1,4-glycosidic bonds and can be induced in pathogenic interactions. But the expression of Unigene 15958_All was not induced by a pathogenic Fusarium isolate (our unpublished data). Unigene8905_All encoded a protein with 55\% identity to class III chitinase of M. truncatula and class III chitinases were found to be expressed predominantly in the arbuscule-containing cells $[14,56]$, where they may suppress plant defense by the reduction of chitin-like elicitors during the formation of functional symbiotic interfaces [57]. The similar role of class III chitinase SvChit3 in OM was recently suggested by Perotto [19]. Thus, these up-regulated chitinases are probably involved in the lysis of fungal cell wall and balancing the symbiosis.

Another notable OM-regulated group was mannosespecific lectins (Unigene4318_All, Unigene529_All, Unigene14222_All). Among these, Unigene4318_All and Unigene529_All showed high-level expression levels in mycorrhizal roots with little expression in the uninoculated control and ZH3A-3 treatments. Antifungal activity against a range of phytopathogenic fungi has been demonstrated for some of mannose-specific lectins both in vitro and in transgenic plants, and they were thus proposed to be part of defense mechanisms against the invading fungus. The strong up-regulation of SvLect3 and SvLect5 in response to mycorrhizal fungi T. calospora in $S$. vomeracea protocorm was recently confirmed by qRTPCR and this was suggested to be part of a mechanism to limit fungal growth in the mycorrhizal protocorm [19]. However, another mannose-specific lectin gene, Unigene14222_All, with 49905.50 RPKM in control roots, was specifically down-regulated by OM fungi. Owing to the multi-functions of plant lectins, the role of these lectins in the orchid mycorrhizal process remains to be established.

Among plant hormones, ethylene (ET), salicylic acid (SA), abscisic acid (ABA), and jasmonic acid (JA) are known to be key elements in fine-tuning the plant defense response during interaction with other organisms $[58,59]$. The inhibitory effect of exogenous ethylene in AM development has been documented and the colonization of host tissues by mutualistic AM fungi such as Rhizophagus irregularis (formerly Glomus intraradices), ectomycorrhizal fungus Laccaria bicolor, or endophytic fungus Piriformospora indica was inhibited by ET [60]. 
However, ET signaling is still essential for nodule formation in Sesbania rostrata and in the initial stages of $P$. indica colonization [61]. Because ethylene-responsive transcription factors (ERF) can function as transcriptional activators and repressors, they are candidates for establishing a balanced defense response to the fungus without preventing growth and development in AM symbiosis [62]. Valadares [20] also suggested the role of ethylene in OM regulation when compared the gene expression pattern of $O$. maculata mycorrhizal roots in comparison to non-mycorrhizal controls [22]. In our global expression profiling, eight transcription factors (TFs) related to ethylene signaling (Table 4) were found to accumulate in all the symbiotic roots and four genes among these were specifically induced in OM roots. Among these, the induction of two transcripts (Unigene1724_All, Unigene12197_All) was further validated by by qRT-PCR. The translated sequence of Unigene1724_All showed 63\% similarity to the ethylene receptor homolog 2 (ETR2) of Zea mays with two-fold induction. Unigene12197_All, encoding a protein with $45 \%$ similarity to ethyleneresponsive element binding factor 4 (ERF4) of G. $\max$, was induced more than 5-fold in the symbiotic roots. As with Plett et al. [60], the induction of these TFs is probably an adaptive response by the plant so that its growth and vigor are not compromised by the fungus in the late stage of symbiosis [60].

ABA plays a crucial role in biotic and abiotic stress responses. Analysis of AM colonization in the sitiens ABA-deficient tomato mutant showed that ABA was necessary in order to complete arbuscule formation and its functionality and to promote sustained colonization of the plant root [63]. Subsequent work supported the notion that $\mathrm{ABA}$ deficiency negatively regulates mycorrhizal intensity/hyphal colonization directly or indirectly through increasing ethylene levels [64-66]. Accumulation of the transcripts related to ABA de novo biosynthesis was documented in AM roots [49] and OM green protocorms [20]. At the same time, genes associated with ABA catabolism also showed increased transcript levels in AM roots[49] and OM roots [22]. In our study, 4 transcripts related to ABA biosynthesis: 9-cis-epoxycarotenoid dioxygenase (NCED) (Unigene1444_All, Unigene2412_All) and zeaxanthin epoxidase (ZXE) (Unigene11284_All, Unigene13062_All), were co-suppressed in symbiotic roots. ABA deficiency might be involved in restriction of fungal spread in orchid symbiotic roots.

Jasmonic acid has long been implicated in the plant's systemic response to pathogen attack [67]. While experimental results sometimes appear contradictory, most authors agree that jasmonate signalling is important for AM colonization and development [68]. Plett [60] revealed that in the interaction between $L$. bicolor and poplar, ethylene and jasmonic acid showed extensive transcriptional cross-talk and functioned as negative modulators during mutualistic symbiosis [60]. Jasmonates belong to a diverse class of lipid metabolites known as oxylipins and the key genes in the biosynthesis of oxylipins were commonly induced in mycorrhizal roots [59]. Consistent with these studies, the induction of 6 lipoxygenase (LOXs) genes in our study suggest the involvement of the oxylipin pathway in regulation of OM symbiosis. In plants, there are two main branches of the oxylipin pathway, determined by two different types of lipoxygenases (LOXs), 9-LOX and 13-LOXs. The 13-LOX pathway leads to the biosynthesis of JA and derivatives, and the relevance of the 9-LOX pathway in plant interactions with nematodes and pathogens has also been demonstrated recently $[69,70]$. Further research is required to elucidate the exact role of these up-regulated LOXs in long-term balance of the OM symbiosis.

Apart from the potential roles for ET, ABA and JA in OM symbiosis, three transcripts associated with gibberellin (GAs) biosynthesis were also increased in abundance in orchid mycorrhizal roots: two genes (Unigene11581_All, Unigene3993_All) encoding gibberellin 3-oxidase (GA3ox) and another (Unigene13170_All) encoding GA 20-oxidase (GA20ox). The translated sequence of Unigene13170_All shares $77 \%$ identity to gibberellin 20-oxidase of Triticum aestivum and its induction was confirmed by qRT-PCR. The product of GA3ox and GA20ox activates GA, suggesting that GA synthesis is essential for OM formation. In barley- $P$. indica interaction, Schäfer [71] also observed that two barley mutants impaired in GA synthesis or perception, reduced colonization by $P$. indica. Similarly, homologues of genes involved in the GA biosynthesis were already identified as mycorrhizal-responsive in tomato plants at the mature (50 dpi) phase of the interaction [66]. Foo [68] reported that biologically active gibberellins suppress arbuscule formation in pea roots, and gibberellin signaling DELLA proteins are essential for this response. Owing to extensive transcriptional cross-talk between GA signaling and SA/JA responses, the GA-regulated defense response might be critical for establishing these long-term mutualisms.

\section{Transcription factors (TF)}

As detailed above, three treatments initiated common stress responses for symbiotic roots, so the majority of co-regulated TFs encoded AP2 domain TFs and ethylene-responsive TFs (ERF), WRKY TFs, Myb- family TFs, basic helix-loop-helix (bHLH) TFs and zinc-finger TFs (Table 4). DNA-binding WRKY, AP2-domain and ERF TFs are generally involved during pathogen-related stress responses $[48,61]$. The co-regulated TFs may also be involved in root developmental process, as are MYB family, ERF and NAC family [72]. 
Table 4 Transcription factors among beneficial fungi- induced genes

\begin{tabular}{|c|c|c|c|}
\hline $\begin{array}{l}\text { TF family } \\
\text { or domain }\end{array}$ & Induced & Repressed & $\begin{array}{l}\text { Number } \\
\text { of genes }\end{array}$ \\
\hline AP2-ERF & $\begin{array}{l}\text { Unigene627_All*, Unigene6402_All*, Unigene12197_All*®, Unigene103_All*, } \\
\text { Unigene1545_All, Unigene10693_All, Unigene13239_All, Unigene13630_All }\end{array}$ & & $4^{*}(4)$ \\
\hline WRKY & $\begin{array}{l}\text { Unigene2569_All } \oplus(\text { WRKY19), Unigene13120_All*(WRKY40), Unigene8345_All* } \\
\text { (WRKY5), Unigene8346_All*(WRKY5), Unigene3004_All*(WRKY39), } \\
\text { Unigene4511_All*(WRKY43), Unigene1640_All(WRKY17) }\end{array}$ & Unigene1887_All (WRKY23) & $5^{*}(3)$ \\
\hline Myb & Unigene10890_All*, Unigene13524_All*, Unigene14312_All*, Unigene2947_All & $\begin{array}{l}\text { Unigene12533_All, Unigene16161_All*, } \\
\text { Unigene1441_All*, Unigene14070_All** }\end{array}$ & $6^{*}(2)$ \\
\hline bHLH & Unigene4212_All*, Unigene2945_All*, Unigene13683_All*, Unigene14108_All* & $\begin{array}{l}\text { Unigene1570_All*, Unigene15208_All*, } \\
\text { Unigene12890_All, }\end{array}$ & $6^{*}(1)$ \\
\hline HOX & Unigene11426_All*, Unigene888_All, & $\begin{array}{l}\text { Unigene9904_All, Unigene7407_All*, } \\
\text { Unigene14238_All }\end{array}$ & $2^{*}(3)$ \\
\hline NAC & Unigene14999_All*®$\oplus$, Unigene8664_All*, Unigene16437_All*, Unigene1 1336_All* & Unigene5046_All* & $5^{*}$ \\
\hline ARF & Unigene10085_All (ARF9), Unigene9466_All (ARF9) & & (2) \\
\hline GRAS & $\begin{array}{l}\text { Unigene2120_All(SC)*, Unigene10121_All, Unigene4453_All (scarecrow-like), } \\
\text { Unigene6482_All (SC), Unigene13312_All (SC), Unigene15630_All, } \\
\text { Unigene456_All }\end{array}$ & & $1^{*}(6)$ \\
\hline BTB/POZ & Unigene2160_All, Unigene351_All, Unigene352_All & Unigene11206_All & (4) \\
\hline $\mathrm{C} 3 \mathrm{H}$ & Unigene156_All, Unigene209_All*, Unigene10727_All* $\oplus$ & Unigene16285_All, Unigene81_All & $2^{*}(3)$ \\
\hline GATA & Unigene1952_All*, Unigene10179_All* & Unigene1691_All, Unigene10219_All** & $3^{*}(1)$ \\
\hline $\mathrm{C} 2 \mathrm{H} 2$ & Unigene2954_All*, & Unigene2352_All* & $2^{*}$ \\
\hline dof & Unigene3028_All*, & & $1^{*}$ \\
\hline A20AN1 & Unigene2954_All*, Unigene10730_All & & $1^{*}(1)$ \\
\hline co-like & & Unigene4931_All & (1) \\
\hline Hsf & Unigene13648_All*, Unigene4980_All** & & $2^{*}$ \\
\hline Trihelix & & Unigene2892_All & (1) \\
\hline ASG & & Unigene3840_All & (1) \\
\hline WD & Unigene4225_All & & (1) \\
\hline MADs & Unigene4681_All & & (1) \\
\hline MACPF & Unigene8197_All & & (1) \\
\hline BLH & Unigene8238_All & & (1) \\
\hline$A-2 b$ & Unigene13648_All*, Unigene4980_All & & $1^{*}(1)$ \\
\hline UNE & Unigene4910_All & Unigene10862_All* & $1^{*}(1)$ \\
\hline if & Unigene14563_All* & & $1^{*}$ \\
\hline MYC & Unigene15000_All* & & $1^{*}$ \\
\hline RAX & Unigene1589_All** & & $1^{*}$ \\
\hline NF-YC & Unigene16018_All* & & $1^{*}$ \\
\hline bZIP & Unigene4820_All, & & (1) \\
\hline
\end{tabular}

Lists of TFs in this table included specifically regulated TFs in OM formation and * co-regulated genes in three treatments; $\oplus$ qPCR validation; number in parenthesis referred to the gene number regulated by OM formation.

We also detected GRAS family and ARF TFs specifically induced by $\mathrm{OM}$ formation. Four transcripts (Unigene4453_All, Unigene6482_All, Unigene13312_All, Unigene15630_All) encoding for GRAS members were putative SCARECROW (SCR) protein encoding genes, considered to be genetic determinants of root identity. Previous studies also confirmed that members of the GRAS family are essential for nodule development [11] and they may be important for the regulation of gene expression in AM roots of M. truncatula, L. japonicus and S. lycopersicum $[11,12,49]$. Two putative ARF transcripts were also identified to be up- regulated in orchid mycorrhizal roots. The induction of putative ARFs has also been found during AM symbiosis in maize, rice and M. truncatula, but not in L. japonicus [72]. And in AM interaction, mycorrhizal roots exhibit morphological characteristics such as an increase in the number of lateral/fine roots during early growth phases, similar to auxin-treated roots 
[49]. Recently, Sukumar (2012) and Fusconi [73] summarized a compelling supportive role for involvement of auxin pathways in beneficial plant-microbe interactions $[73,74]$. Chutima [75] reported that orchid-associated fungi Tulasnella sp. produced high levels of indole-3acetic acid (IAA) with all biological activities in culture medium supplemented with $2 \mathrm{mg} / \mathrm{ml}$ of L-tryptophan [75]. The IAA production by isolates ML01 was also identified in our research group (unpublished data).Furthermore, Unigene11039_All, predicted to translate a protein with $66 \%$ similarity to an auxin efflux facilitator SIPIN1 of Solanum lycopersicum, showed 15-fold up-regulation in the symbiotic roots. All these data point to the probable involvement of auxin signaling pathway in OM functionality.

\section{DEGs specifically regulated by non-mycorrhizal fungus ZH3A-3}

The hyphae of non-mycorrhizal fungus ZH3A-3 colonized the velamen cells of orchid roots and individual inoculation significantly improved the root length and FW of C. hybridum plantlets. As detailed above, 845 genes were significantly regulated in C. hybridum roots inoculated with ZH3A-3 alone and most of these DEGs were shared with those of ML01 and/or MZ treatment. Apart from these shared DEGs, we also identified 143 genes were specifically regulated by ZH3A-3 treatment.

The largest number of up-regulated transcripts by ZH3A-3 treatment was associated with orchid root development. These genes are mainly related to hormonal balance and transcription regulation. Among plant phytohormones, auxin, cytokinin, and ethylene play important role for root development. Consistent with this, we detected the up-regulation of many corresponding genes, which encoded one cytokinin dehydrogenase (Unigene14465_All), two ERF (Unigene15166_All, Unigene7827_All), and three ABC transporter B family members (Unigene16320_All, Unigene5921_All, Unigene14693_All). Auxin plays a pivotal role in many plant- beneficial microbe interactions [74], and it is well established that higher auxin/cytokinin ratio determines the root initiation. A recent study also clearly demonstrated that $O s C K X 4$, a cytokinin oxidase/dehydrogenase (CKX) family gene, integrates cytokinin and auxin signaling to control rice crown root formation positively [76]. So, the up-regulation of Unigene14465_All, which encodes a homolog with $69 \%$ identity to CKX of $A$. thaliana, may suggest its positive role in orchid- $\mathrm{ZH} 3 \mathrm{~A}-3$ interaction. Polar auxin transport (PAT) is essential for establishment of auxin gradient that spatially defines the quiescent center (QC) and consequently the fate of neighboring stem [77]. ABC transporter B family members were probably involved in auxin acropetal or basipetal transport [78], thus, the up-regulation of three $\mathrm{ABC}$ transporter $\mathrm{B}$ family members appears to converge on the auxin pathway to modulate root development. As shown in Table 4, the putative MYB-TFs ranked the third largest number of the regulated TFs in the mycorrhizal symbiosis, and most were shared by three treatments, which suggested their essential role in response to symbiotic fungi. Recently, a convincing research supported that a putative MYB-like TF of $L$. japonicus (LjMAMI) which was AM-responsive may also have non-symbiotic functions: i.e. root growth [79]. In our study, two transcripts (Unigene2947_All and Unigene1589_All),encoding homologues of Myb family TFs of $O$. sativa Japonica Group and A. thaliana with $60 \%$ - $80 \%$ identity, were also detected to be upregulated 4-fold by $\mathrm{ZH} 3 \mathrm{~A}-3$. The translated sequence of Unigene2947_All also shared 46\% similarity to LjMAMI at amino acid level. Another up-regulated TF related to root development was Unigene489_All (upregulated 2 -fold), which encodes a protein with $45 \%$ similarity to SCARECROW-like protein of $Z$. mays.

We also identified a substantial number of genes related to general disease resistance processes which were specifically up-regulated by ZH3A-3 treatment. These included 3 transcripts related to signaling (leucine-rich repeat transmembrane protein kinase), 5 transcripts associated with balance of reactive oxygen (respiratory burst oxidase homolog, class III peroxidase, L-ascorbate oxidase, monocopper oxidase-like protein), and 12 transcripts involved in secondary metabolism (phenylalanine ammonia-lyase, DnaJ homolog, disease resistance response protein, isoflavone 2'-hydroxylase, syringomycin biosynthesis enzyme). The increased activity of chitinases were generally found in nonspecific, broad-spectrum defenses, but we did not detect the transcript accumulation of chitinase genes in CyEX22.The fungal cell wall of isolate $\mathrm{ZH} 3 \mathrm{~A}-3$ always ruptured as the cultivation proceeded (our unpublished data), which might be the reason. The activation of basal defense mechanisms of orchid plants by beneficial fungus $\mathrm{ZH} 3 \mathrm{~A}-3$ did not affect the symbiotic effects, as described in [80].

As ZH3A-3 colonization induced dramatic structural changes in root cells and promoted the root growth of orchids, transcripts accumulated in the symbiotic roots were also related to carbohydrate and amino acid metabolism, protein synthesis and processing, and structural reorganization. Furthermore, a transcript (Unigene15068_All) involved in water transport was also up-regulated, which encodes a homolog of aquaporin PIP1-2 of $Z$. mays with $87 \%$ identity.

Taken together, we confirmed the findings which suggested that the development and metabolism of plant symbionts are generally driven by differential regulation of transcriptional regulators, signal transduction, and metabolic pathways, rather than by expression of symbiosis-specific genes [81]. 


\section{Detection of putative fungal genes in symbiotic roots}

Owing to the distinct phylogenetic relationship between isolate ML01 and ZH3A-3, we could detect 163 possible fungal genes combining the annotation information of de novo assembled transcripts with the comparative expressed level in different symbiotic roots (Additional file 18: Tables S15 and S16). Of these 163 genes, 53 were probably genes from isolate $\mathrm{ZH} 3 \mathrm{~A}-3$, and the rest, from ML01. The origin of putative ML01 genes was further confirmed by Blastn search against the $T$. calospora draft genome or $T$. calospora mycelium ESTs with an E value $>1 \mathrm{e}^{-20}$ (http://genome.jgi.doe.gov/pages/blast.jsf? $\mathrm{db}=$ Tulca1).

Transcripts from ML01 in the mycorrhizal roots were largely assigned to ribosomal proteins, enzymes that might be involved in plant cell wall degradation (1,4-betacellobiosidase A) and remodeling the fungal cell wall during growth and symbiosis (glycosyltransferase family 2 protein, chitin deacetylase, UDP-glucose pyrophosphorylase, endo-beta-mannanase 4). We also identified numerous transcripts encoding different proteins associated with the nutrient transport and assimilation, such as $\mathrm{H}^{+}$-transporting ATPase, phosphate transporter (Unigene5906_All), ammonium transporter (Unigene2660_All), amino acid and protein transporters, ZIP-like iron-zinc transporter, monosaccharide transporters (Unigene4644_All, Unigene12394_All) and MFS-type transporters (Unigene16198_All, Unigene2162_All). ABC-type $\mathrm{Fe}^{3+}$-siderophore transporter and other transporters most probably implicated in the detoxification process were also detected in the mycorrhizal roots. The translated amino acid sequence of Unigene5906_All shared $59-60 \%$ identity to high-affinity $\mathrm{Pi}$ - transporters from $G$. versiforme (GvePT) and $R$. intraradices (RinPT) (Additional file 19: Figure S11). The function of RinPT (also GinPT in references) has been suggested by Tisserant et al. [82] to be involved in stabilizing cooperation in the mycorrhizal symbiosis [82]. The transcript abundance of Unigene5906_All in CyEX23 was higher than that in CyEX21. So, this gene might be responsible for the better growthpromoting effect of MZ treatment than that of ML01 alone. Besides the transcripts in $\mathrm{N}$ and $\mathrm{P}$ assimilation pathway, ironzinc transporter and $\mathrm{ABC}$-type $\mathrm{Fe}^{3+}$-siderophore transporter co-existed in the mycorrhizal roots, which suggest an important role of some metals in OM functionality. Our previous study showed that isolate CL01, Tulasnella-like Rhizoctonia, formed typical mycorrhizae with orchids and enhanced the N, P, Zn, Fe contents of mycorrhzial plants [8]. The ITS sequence of ML01 shared $84 \%$ similarity to that of isolate CL01 and both functioned similarly in improving the growth and nutritional absorption of orchid plantlets (our unpublished data). However, there is a need to compare the differences in gene expression between the intraradical and extraradical mycelium so as to elucidate the role of these transcripts in OM symbiosis.

\section{Conclusions}

Using a combination of RNA-seq and real-time RT-PCR, we characterized the root transcriptomic reprogramming of $C$. hybridum with respect to different beneficial fungi and identified specific changes in relative abundance for transcripts of genes in OM symbiosis. Genes involved in cell wall modification, reactive oxygen species detoxification, defense-related phytohormone and phosphate transport were co- induced in all the symbiotic interactions. The transcripts increased specifically by OM were related to signaling (LysM domain receptor-like kinase 3-like), cell wall degradation or reinforcement, protein metabolism and processing, defense (chitinase and mannosespecific lectin) and N, Fe transport. Among these DEGs, genes potentially functioned in $\mathrm{C}, \mathrm{N}, \mathrm{P}$ and Fe transport, hormone metabolism and signaling are of particular interest. Aside from these orchid transcripts, we also identified some putative fungal genes in symbiotic roots which were associated with plant cell wall degradation, remodeling the fungal cell wall and nutrient transport. This comprehensive dataset provides a basis for future research in exploring the molecular mechanisms underlying OM formation and functionality.

\section{Additional files}

Additional file 1: Table S1. Identities of the selected reference assemblies with Sanger-sequencing results of corresponding touch-down PCR products. Additional file 2: Table S2. Gene-specific primers used for QRT-PCR.

Additional file 3: Figure S1. Typical co-cultivation condition of Cymbidium hybridum plantlets with different fungi at 15 dpi. Mock-inoculated control (A) and inoculated with isolate Ml01 (B), ZH3A-3 (C) and ML01 + ZH3A-3 (D).

Additional file 4: Figure S2. Root staining results of each treatment at different symbiotic time points. (A) Roots inoculated with E. repens isolate ML01 at 6 days post-inoculation (dpi); (B) Roots inoculated with U. nana isolate ZH3A-3 at $6 \mathrm{dpi}$ (C) Roots inoculated with isolates ML01 and ZH3A-3 at 6 dpi; (D) Mock-inoculated roots at 6 dpi; (E) Roots inoculated with E. repens isolate ML01 at $10 \mathrm{dpi}$ (F) Roots inoculated with U. nana isolate ZH3A-3 at $10 \mathrm{dpi}$ (G) Roots inoculated with isolates ML01 and ZH3A-3 at 10 dpi; (H) Mock-inoculated roots at 10 dpi; (I) Roots inoculated with E. repens isolate ML01 at $15 \mathrm{dpi}$ ( $\mathbf{( J )}$ Roots inoculated with $U$. nana isolate ZH3A-3 at 15 dpi; (K) Roots inoculated with isolates ML01 and ZH3A-3 at 15 dpi; (L) Mock-inoculated roots at 15 dpi; (M) Roots inoculated with E. repens isolate ML01 at $30 \mathrm{dpi}$; (N) Roots inoculated with U. nana isolate ZH3A-3 at 30 dpi; (O) Roots inoculated with isolates ML01 and ZH3A-3 at 30 dpi; (P) Mock-inoculated roots at $30 \mathrm{dpi}$.

Additional file 5. Cymbidium hybridum root transcriptome assemblyIllmina 90 bp reads.

Additional file 6: Table S3. Highly abundant transcripts in CyTr-unigenes (Top 50).

Additional file 7: Table S4. Pathway annotation of CyTr-unigenes.

Additional file 8: Table S5. Statistics of DGE sequencing.

Additional file 9: Table S6. Statistics of uniquely mapped reads for each sample.

Additional file 10: Table S7-S9. Lists of differentially expressed genes in different C. hybridum- beneficial fungi interactions.

Additional file 11: Table S10. Top 100 abundant genes in symbiotic roots with positive fold change in response to symbiotic fungi. Table S11. 
Top 100 abundant genes in non-symbiotic roots with negative fold change in response to symbiotic fungi.

Additional file 12: Figure S3. Hierarchical clustering of DEGs from C. hybridum expressed in the roots in response to isolates ML01 (CyEX21), ZH3A-3 (CyEX22), MLO1 + ZH3A-3 (CyEX23)or mock inoculation (CyEX20).

Additional file 13: Lists of DEGS in 20 sub-clusters based on k-means. Additional file 14: Figure S4-S6. GO enrichment bar graphs of DEGs in the interactions between C. hybridum and ML01 (S4), ZH3A-3 (S5) or $\mathrm{MLO} 1+$ ZH3A-3 (S6).

Additional file 15: Table S12-S14. Lists of enriched pathways in different C. hybridum- beneficial fungi interactions.

Additional file 16: Figure S7-S9. Scatterplot for top 20 enriched KEGG pathways of DEGs in the interactions between C. hybridum and ML01 (S7), ZH3A-3 (S8) or ML01 + ZH3A-3 (S9).

Additional file 17: Figure S10. Comparison of expression profiles of random selected 26 genes by RNA-seq and QRT-PCR.

Additional file 18: Table S15. Expression data for putative genes from E. repens isolate MLO1 in symbiotic roots. Table S16. Expression data for putative genes from $U$. nana isolate $\mathrm{ZH} 3 \mathrm{~A}-3$ in symbiotic roots.

Additional file 19: Figure S11. Phylogenetic tree for the amino acid sequences of symbiosis- associated phosphate transporters from plant and fungi.The dendrogram was generated by Mega 4.0 software using ClustIW for the alignment and the neighbor-joining method for the construction of phylogeny. The plant Pi-transporters accession numbers could be obtained in [49]. Fungal phosphate transporters accession numbers: Glomus versiforme: GvePT, AAC49132.1; GvePT2, gi|74654973; Rhizophagus intraradices: RinPT, AAL37552.1; Yeast: YEPHO84, gil 1346710; Sesbania rostrata: SerPT, CAC28219.1; Piriformospora indica: PiPT1, ABI93950.1; PiPT2, CCA74169.1; PiPT3, CCA74178.1; PiPT4, CCA76379.1. The nucleotide sequences of putative phosphate transporters in our study were available in Additional file 6: Table S3.

\section{Abbreviations}

ABC: ATP-binding cassette; AMs: Arbuscular mycorrhizas; AP2/ERF: APETALA2/ ET response factor; ARF: Auxin response factor; bHLH: Basic helix-loop-helix; CAT5: Cationic amino acid transporter 5; CDPK: Calcium-dependent protein kinase; CKX: Cytokinin oxidase/dehydrogenase; DEGs: Differentially expressed genes; DGE: Digital Gene Expression; ECMs: Ectomycorrhizas; ETR: Ethylene receptor homolog; LHT1: Lysine histidine transporter 1; LysM-RLK: LysMdomain containing receptor-like kinases; MAF: Mycorrhizal- associated fungi; MD: Mycorrhizal dependency; MH: Heterotrophy; MX: Mixotrophs; NAATAA: Nicotianamine aminotransferase A; NGS: Next generation sequencing; NSP2: Nodulation-signaling pathway 2 protein; OM: Orchid mycorrhizae; OMF: Orchid mycorrhizal fungi; OPT: Oligopeptide transporter family; PAT: Polar auxin transport; PDA: Potato-dextrose agar;

PDCD: Programmed cell death protein 4; PT: Phosphate transporter; PTR: Peptide transporter; PRG: Percentage of root growth; QC: Quiescent center; RAM1: Protein required for arbuscular mycorrhization 1; RMBT: Reads that could be mapped back to transcripts; RPKM: Reads per kilo base per million reads; SCR: SCARECROW; SPA: Suppressor of phyA-105:

TFs: Transcription factors; TMT2: Tonoplast monosaccharide transporter 2; VAMP7B: Vesicle-associated membrane protein 7B; XET: Xyloglucan endotransglucosylase.

\section{Competing interests}

The authors declare that they have no competing interests.

\section{Authors' contributions}

ZXL and ZJX carried out the experiments, performed the bioinformatics analyses, and drafted the manuscript. CCL cultured the experimental material and extracted all the RNA samples. ZHY performed the symbiotic experiments. YJZ and LM participated in the GRT-PCR experiment. LFB designed the study and revised the manuscript. All authors read and approved the final manuscript.

\section{Acknowledgments}

We are grateful to Xiaoyong Liu (Institute of Microbiology, Chinese Academy of Sciences) for his help with the identification of fungal isolates in our research. We thank Professor Ronald R. Sederoff (Department of Forestry and Environmental Resources, NC State University, USA) for his critical reading and revision of the manuscript. We also thank for the constructive comments of the anonymous reviewers to improve our manuscript. This research was financially supported by National Natural Science Foundation of P. R. China (Grant No. 31170654 and 31101572), Guangdong Province Science and Technology Project (Grant No. 2007A020200004-7), and the Cooperation Project in Industry, Education and Research of Guangdong Province and Ministry of Education of P. R. China (Grant No.

2011 B090400239), and the Science and Technology Fund from South China Agricultural University (K08032).

\section{Author details}

'Guangdong Key Laboratory for Innovative Development and Utilization of Forest Plant Germplasm, South China Agricultural University, Wushan Road 483, Tianhe District, Guangzhou 510642, People's Republic of China. ${ }^{2}$ Key Laboratory of South China Agricultural Plant Genetics and Breeding, South China Botanical Garden, The Chinese Academy of Sciences, Guangzhou 510650, People's Republic of China. ${ }^{3}$ Guangdong Key Laboratory of Ornamental Plant Germplasm Innovation and Utilization, Environmental Horticulture Research Institute, Guangdong Academy of Agricultural Sciences, East 1st Street 1, Jinying Road, Tianhe District, Guangzhou 510640, People's Republic of China.

Received: 16 March 2014 Accepted: 22 August 2014

Published: 31 August 2014

\section{References}

1. Rasmussen HN: Terrestrial Orchids from Seed to Mycotrophic Plant. Cambridge: Cambridge University Press; 1995.

2. Smith SE, Read DJ: Mycorrhizal Symbiosis. Cambridge: Academic; 2008.

3. Dearnaley JDW, Martos F, Selosse MA: Orchid mycorrhizas: molecular ecology, physiology, evolution and conservation aspects. In Fungal Associations. 2nd edition. Berlin Heidelberg: Springer-Verlag; 2012.

4. Selosse MA, Roy ML: Green plants that feed on fungi: facts and questions about mixotrophy. Trends Plant Sci 2009, 14(2):64-70.

5. Rasmussen HN, Rasmussen FN: Orchid mycorrhiza: implications of a mycophagous life style. Oikos 2009, 118(3):334-345.

6. Motomura H, Selosse MA, Martos F, Kagawa A, Yukawa T: Mycoheterotrophy evolved from mixotrophic ancestors: evidence in Cymbidium (Orchidaceae). Ann Bot 2010, 106:573-581.

7. Dong F, Zhao JN, Liu HX: Effects of fungal elicitors on the growth of the tissue culture of Cymbidium goeringii. North Hortic 2008, 5:194-196

8. Zhao XL, Yang JZ, Liu S, Chen CL, Zhu HY, Cao JX: The colonization patterns of different fungi on roots of Cymbidium hybridum plantlets and their respective inoculation effects on growth and nutrient uptake of orchid plantlets. World J Microbiol Biotechnol 2014, 30(7):1993-2003.

9. Cameron DD, Leake JR, Read DJ: Mutualistic mycorrhiza in orchids: evidence from plant-fungus carbon and nitrogen transfers in the greenleaved terrestrial orchid Goodyera repens. New Phytol 2006, 171:405-416.

10. Cameron DD, Johnson I, Read DJ, Leake JR: Giving and receiving: measuring the carbon cost of mycorrhizas in the green orchid, Goodyera repens. New Phytol 2008, 180:176-184.

11. Guether M, Balestrini R, Hannah M, He J, Udvardi MK, Bonfante P: Genome-wide reprogramming of regulatory networks, transport, cell wall and membrane biogenesis during arbuscular mycorrhizal symbiosis in Lotus japonicus. New Phytol 2009, 182:200-212.

12. Gomez SK, Javot H, Deewatthanawong P, Torres-Jerez I, Tang Y, Blancaflor EB, Udvardi MK, Harrison MJ: Medicago truncatula and Glomus intraradices gene expression in cortical cells harboring arbuscules in the arbuscular mycorrhizal symbiosis. BMC Plant Biol 2009, 9:48.

13. Czaja LF, Hogekamp C, Lamm PMF, Martinez EA, Samain E, Dénarié J, Küster H, Hohnjec N: Transcriptional responses toward diffusible signals from symbiotic microbes reveal MtNFP- and MtDMI3dependent reprogramming of host gene expression by arbuscular mycorrhizal fungal lipochitooligosaccharides. Plant Physiol 2012, 159:1671-1685.

14. Hogekamp C, Arndt D, Pereira PA, Becker JD, Hohnjec N, Küster H: Laser microdissection unravels cell-type-specific transcription in arbuscular mycorrhizal roots, including CAAT-box transcription factor gene 
expression correlating with fungal contact and spread. Plant Physio/ 2011, 157:2023-2043.

15. Bonfante $P$, Genre A: Mechanisms underlying beneficial plant-fungus interactions in mycorrhizal symbiosis. Nat Commun 2010, 1:48.

16. Heller G, Adomas A, Li G, Osborne J, Van Zyl L, Sederoff R, Finlay RD, Stenlid J, Asiegbu FO: Transcriptional analysis of Pinus sylvestris roots challenged with the ectomycorrhizal fungus Laccaria bicolor. BMC Plant Biol 2008, 8:19.

17. Monterroso AF, Canales J, Torre FDL, A'vila C, Francisco M, Ca'novas FM: Identification of genes differentially expressed in ectomycorrhizal roots during the Pinus pinaster-Laccaria bicolor interaction. Planta 2013, 237:1637-1650.

18. Li B, Tang MJ, Tang K, Zhao LF, Guo SX: Screening for differentially expressed genes in Anoectochilus roxburghii (Orchidaceae) during symbiosis with the mycorrhizal fungus Epulorhiza sp. Sci China Life Sci 2012, 55:164-171.

19. Perotto S, Rodda M, Benetti A, Sillo F, Ercole E, Girlanda M, Murat C, Balestrini R: Gene expression in mycorrhizal orchid protocorms suggests a friendly plant-fungus relationship. Planta 2014, 239(6):1337-1349.

20. Valadares RB, Perotto S, Santos EC, Lambais MR: Proteome changes in Oncidium sphacelatum (Orchidaceae) at different trophic stages of symbiotic germination. Mycorrhiza 2014, 24(5):349-360.

21. Zhao MM, Zhang G, Zhang DW, Hsiao YY, Guo SX: ESTs analysis reveals putative genes involved in symbiotic seed germination in Dendrobium officinale. PLOS One 2013, 8(8):e72705.

22. Valadares RBS: Identification of genes and proteins involved in the regulation of orchid mycorrhiza. In Doctoral Thesis in Solos e Nutrição de Plantas. Piracicaba: Escola Superior de Agricultura Luiz de Queiroz, University of São Paulo; 2014

23. Taylor DL, Bruns TD, Szaro TM, Hodges SA: Divergence in mycorrhizal specialization within Hexalectris spicata (Orchidaceae), a nonphotosynthetic desert orchid. Am J Bot 2003, 90(8):1168-1179.

24. Fu CH, Chen YW, Hsiao YY, Pan ZJ, Liu ZJ, Huang YM, Tsai WC, Chen HH: OrchidBase: a collection of sequences of the transcriptome derived from orchids. Plant Cell Physiol 2011, 52(2):238-243.

25. Su CL, Chao YT, Yen SH, Chen CY, Chen WC, Chang YC, Shih MC: Orchidstra: an integrated orchid functional genomics database. Plant Cell Physiol 2013, 54(2):e11.

26. Zhang JX, Wu KL, Zeng SJ, da Silva T, Zhao XL, Tian CE, Xia HQ, Duan J: Transcriptome analysis of Cymbidium sinense and its application to the identification of genes associated with floral development. BMC Genomics 2013, 14:1.

27. Dijk $E$, Eck ND: Effects of mycorrhizal fungi on in vitro nitrogen response of some Dutch indigenous orchid species. Can J Bot 1995, 73:1203-1211.

28. Long LK, Yao Q, Huang YH, Yang RH, Guo J, Zhu HH: Effects of arbuscular mycorrhizal fungi on zinnia and the different colonization between Gigaspora and Glomus. World J Microbiol Biotechnol 2010, 26(8):1527-1531.

29. Feng C, Chen M, Xu CJ, Bai L, Yin XR, Li X, Chen KS: Transcriptomic analysis of Chinese bayberry (Myrica rubra) fruit development and ripening using RNA-Seq. BMC Genomics 2012, 13(1):19.

30. Xu DL, Long H, Liang JJ, Zhang J, Chen X, Li JL, Pan ZF, Den GB, Yu MQ: De novo assembly and characterization of the root transcriptome of Aegilops variabilis during an interaction with the cereal cyst nematode. BMC Genomics 2012, 13:133.

31. Birol I, Jackman SD, Nielsen CB, Qian JQ, Varhol R, Stazyk G, Morin RD, Zhao $Y$, Hirst M, Schein JE, Horsman DE, Connors JM, Gascoyne RD, Marra MA, Jones SJ: De novo transcriptome assembly with ABySS. Bioinformatics 2009, 25(21):2872-2877.

32. Grabherr MG, Haas BJ, Yassour M, Levin JZ, Thompson DA, Amit I, Adiconis X, Fan L, Raychowdhury R, Zeng Q, Chen Z, Maucele E, Gnirle A, Rhind N, di Palma F, Birren BW, Nusbaum C, Lindblad-Toh K, Friedman N, Regev A: Full-length transcriptome assembly from RNA-Seq data without a reference genome. Nat Biotechnol 2011, 29(7):644-652

33. Mortazavi A, Williams BA, McCue K, Schaeffer L, Wold B: Mapping and quantifying mammalian transcriptomes by RNA-Seq. Nat Methods 2008, 5:621-628.

34. Robinson M, Oshlack A: A scaling normalization method for differential expression analysis of RNA-seq data. Genome Biol 2010, 11:3.

35. Jiang $\mathrm{H}$, Wong $\mathrm{WH}$ : SeqMap: mapping massive amount of oligonucleotides to the genome. Bioinformatics 2008, 24(20):2395-2396.

36. Jiang $\mathrm{H}$, Wong $\mathrm{WH}$ : Statistical inferences for isoform expression in RNA-Seq. Bioinformatics 2009, 25(8):1026-1032.
37. Mutasa-Göttgens ES, Joshi A, Holmes FH, Peter HP, Göttgens B: A new RNASeq-based reference transcriptome for sugar beet and its application in transcriptome-scale analysis of vernalization and gibberellin responses. BMC Genomics 2012, 13:99.

38. Shi CY, Yang H, Wei CL, Yu O, Zhang ZZ, Jiang CJ, Sun J, Li YY, Chen Q, Xia T, Wan XC: Deep sequencing of the Camellia sinensis transcriptome revealed candidate genes for major metabolic pathways of tea-specific compounds. BMC Genomics 2011, 12:1.

39. Wang XW, Luan JB, Li JM, Bao YY, Zhang CX, Liu SS: De novo characterization of a whitefly transcriptome and analysis of its gene expression during development. BMC Genomics 2010, 11:400.

40. Liu HX, Luo YB, Liu H: Studies of mycorrhizal fungi of Chinese orchids and their role in orchid conservation in China- a review. Bot Rev 2010, 76:241-262.

41. Hossain MM, Kant R, Van PT, Winarto B, Zeng S, da Silva JA T: The application of biotechnology to orchids. Crit Rev Plant Sci 2012, 32(2):69-139.

42. Kuga $Y$, Sakamoto $N$, Yurimoto $H$ : Stable isotope cellular imaging reveals that both live and degenerating fungal pelotons transfer carbon and nitrogen to orchid protocorms. New Phytol 2014, 202(2):594-605.

43. Gough C, Cullimore J: Lipo-chitooligosaccharide signaling in endosymbiotic plant-microbe interactions. Mol Plant-Microbe Interact 2011, 24(8):867-878.

44. Lohmann GV, Shimoda Y, Nielsen MW, Jorgensen FG, Grossmann C, Sandal N, Sorensen K, Thirup S, Madsen LH, Tabata S, Sato S, Stougaard J, Radutoiu S: Evolution and regulation of the Lotus japonicus LysM receptor gene family. Plant-Microbe Interact 2010, 23:510-521

45. Oldroyd GE: Speak, friend, and enter: signalling systems that promote beneficial symbiotic associations in plants. Nat Rev Microbiol 2013, 11(4):252-263.

46. Poovaiah BW, Du L, Wang H, Yang T: Recent advances in calcium/ calmodulin-mediated signaling with an emphasis on plant-microbe interactions. Plant Physiol 2013, 163(2):531-542.

47. Taylor NG: Cellulose biosynthesis and deposition in higher plants. New Phytol 2008, 178(2):239-252.

48. Gaude N, Bortfeld S, Duensing N, Lohse M, Krajinski F: Arbuscule-containing and non-colonized cortical cells of mycorrhizal roots undergo a massive and specific reprogramming during arbuscular mycorrhizal development. Plant J 2012, 69(3):510-528.

49. Fiorilli V, Catoni M, Miozzi L, Novero M, Accotto GP, Lanfranco L: Global and cell-type gene expression profiles in tomato plants colonized by an arbuscular mycorrhizal fungus. New Phytol 2009, 184:975-987.

50. Cameron DD, Irene J, Jonathan RL, David JR: Mycorrhizal acquisition of inorganic phosphorus by the green-leaved terrestrial orchid. Goodyera repens Ann Bot 2007, 99:831-834.

51. Xie X, Huang W, Liu F, Tang N, Liu Y, Lin H, Zhao B: Functional analysis of the novel mycorrhiza-specific phosphate transporter AsPT1 and PHT1 family from Astragalus sinicus during the arbuscular mycorrhizal symbiosis. New Phytol 2013, 198(3):836-852

52. Zhang Q, Blaylock LA, Harrison MJ: Two Medicago truncatula half-ABC transporters are essential for arbuscule development in arbuscular mycorrhizal symbiosis. Plant Cell 2010, 22:1483-1497.

53. Reinecke $\mathrm{T}$, Kindl $\mathrm{H}$ : Characterization of bibenzyl synthase catalysing the biosynthesis of phytoalexins of orchids. Phytochemistry 1993, 35(1):63-66

54. Song $X$, Zhang X, Wang X, Zhu F, Guo C, Wang Q, Shi Y, Wang J, Chen Y, Zhang L: Tumor suppressor gene PDCD4 negatively regulates autophagy by inhibiting the expression of autophagy-related gene ATG5. Autophagy 2013, 9(5):743-755

55. Mochida K, Yoshida T, Sakurai T, YamaguchiS K, Shinozaki K, Tran LSP: Genome-wide analysis of two-component systems and prediction of stress-reponsive two-component system members in soybean. DNA Res 2010, 17(5):303-324.

56. Bonanomi A, Wiemken A, Boller T, Salzer P: Local induction of a mycorrhiza-specific class III chitinase gene in cortical root cells of Medicago truncatula containing developing or mature arbuscules. Plant Biol 2001, 3:194-200.

57. Salzer P, Bonanomi A, Beyer K, Vogeli-Lange R, Aeschbacher RA, Lange J, Wiemken A, Kim D, Cook DR, Boller T: Differential expression of eight chitinase genes in Medicago truncatula roots during mycorrhiza formation, nodulation, and pathogen infection. Mol Plant Microbe Interact 2000, 13(7):763-777.

58. Pieterse CMJ, Leon-Reyes A, Van der Ent S, Van Wees SCM: Networking by small-molecule hormones in plant immunity. Nat Chem Biol 2009, 5:308-316. 
59. Lopez-Raez JA, Verhage A, Fernandez I, Garcia JM, Azcon-Aguilar C, Flors V Pozo MJ: Hormonal and transcriptional profiles highlight common and differential host responses to arbuscular mycorrhizal fungi and the regulation of the oxylipin pathway. J Exp Bot 2010, 61(10):2589-2601.

60. Plett JM, Khachane A, Ouassou M, Sundberg B, Kohler A, Martin F: Ethylene and jasmonic acid act as negative modulators during mutualistic symbiosis between Laccaria bicolor and Populus roots. New Phytol 2014 202(1):270-286.

61. Khatabi B, Molitor A, Lindermayr C, Pfiffi S, Durner J, Von Wettstein D, Kogel $\mathrm{KH}$, Schäfer P: Ethylene supports colonization of plant roots by the mutualistic fungus Piriformospora indica. PLoS One 2012, 7:4.

62. Fracetto $\mathrm{GG}$, Peres LE, Mehdy MC, Lambais MR: Tomato ethylene mutants exhibit differences in arbuscular mycorrhiza development and levels of plant defense-related transcripts. Symbiosis 2013, 60(3):155-167.

63. Herrera-Medina MJ, Steinkellner S, Vierheilig H, Ocampo Bote JA, Garcia Garrido JM: Abscisic acid determines arbuscule development and functionality in the tomato arbuscular mycorrhiza. New Phytol 2007, 175(3):554-564.

64. Martin-Rodriguez JA, Leon-Morcillo R, Vierheilig H, Ocampo JA, LudwigMuller J, Garcia-Garrido JM: Ethylene-dependent/ethylene-independent ABA regulation of tomato plants colonized by arbuscular mycorrhiza fungi. New Phytol 2011, 190(1):193-205.

65. Rodriguez JA, Morcillo RL, Vierheilig H, Ocampo JA, Ludwig-Muller J, Garrido JM: Mycorrhization of the notabilis and sitiens tomato mutants in relation to abscisic acid and ethylene contents. J Plant Physiol 2010, 167(8):606-613.

66. Garrido JM, Morcillo RJ, Rodriguez JA, Bote JA: Variations in the mycorrhization characteristics in roots of wild-type and ABA-deficient tomato are accompanied by specific transcriptomic alterations. Mol Plant Microbe Interact 2010, 23(5):651-664.

67. Halim VA, Eschen-Lippold L, Altmann S, Birschwilks M, Scheel D, Rosahl S: Salicylic acid is important for basal defense of Solanum tuberosum against Phytophthora infestans. Mol Plant Microbe Interact 2007, 20(11):1346-1352.

68. Foo E, Ross JJ, Jones WT, Reid JB: Plant hormones in arbuscular mycorrhizal symbioses: an emerging role for gibberellins. Ann Bot 2013, 111(5):769-779.

69. Gao X, Starr J, Gobel C, Engelberth J, Feussner I, Tumlinson J, Kolomiets M: Maize 9-lipoxygenase ZmLOX3 controls development, root-specific expression of defense genes, and resistance to root-knot nematodes. Mol Plant Microbe Interact 2008, 21(1):98-109.

70. Vellosillo T, Martinez M, Lopez MA, Vicente J, Cascon T, Dolan L, Hamberg $M$, Castresana C: Oxylipins produced by the 9-lipoxygenase pathway in Arabidopsis regulate lateral root development and defense responses through a specific signaling cascade. Plant Cell 2007, 19(3):831-846.

71. Schäfer P, Pfiffi S, Voll LM, Zajic D, Chandler PM, Waller F, Scholz U, PonsKuhnemann J, Sonnewald S, Sonnewald U, Kogel KH: Manipulation of plant innate immunity and gibberellin as factor of compatibility in the mutualistic association of barley roots with Piriformospora indica. Plant J 2009, 59(3):461-474

72. Formey D, Jourda C, Roux C, Delaux PM: What the genomics of arbuscular mycorrhizal symbiosis teaches us about root development. In Root genomics and soil interactions. Oxford: Blackwell; 2013:171-188.

73. Fusconi A: Regulation of root morphogenesis in arbuscular mycorrhizae: what role do fungal exudates, phosphate, sugars and hormones play in lateral root formation? Ann Bot 2014, 113(1):19-33.

74. Sukumar P, Legue V, Vayssieres A, Martin F, Tuskan GA, Kalluri UC: Involvement of auxin pathways in modulating root architecture during beneficial plant-microorganism interactions. Plant Cell Environ 2013, 36(5):909-919.

75. Chutima R, Lumyong S: Production of indole-3-acetic acid by Thai native orchid-associated fungi. Symbiosis 2012, 56:35-44.

76. Gao S, Fang J, Xu F, Wang W, Sun X, Chu J, Cai B, Feng Y, Chu C: Cytokinin oxidase/dehydrogenase 4 integrates cytokinin and auxin signaling to control rice crown root formation. Plant Physiol 2014, 165(3):1035-1046.

77. Desbrosses Guilhem J, Stougaard J: Root nodulation: a paradigm for how plant-microbe symbiosis influences host developmental pathways. Cell Host Microbe 2011, 10(4):348-358.

78. Blakeslee JJ, Bandyopadhyay A, Lee OR, Mravec J, Titapiwatanakun B, Sauer M, Makam SN, Cheng Y, Bouchard R, Adamec J, Gesler M, Nagashima A, Sakai T, Martinoia E, Friml J, Peer WA, Murphy AS: Interactions among
PIN-FORMED and P-glycoprotein auxin transporters in Arabidopsis. The Plant Cell 2007, 19(1):131-147.

79. Volpe V, Dell'Aglio E, Giovannetti M, Ruberti C, Costa A, Genre A, Guether M, Bonfante P: An AM-induced, MYB-family gene of Lotus japonicus (LjMAMI) affects root growth in an AM-independent manner. Plant J 2013, 73(3):442-455

80. Campos-Soriano L, García-Garrido JM, Segundo BS: Activation of basal defense mechanisms of rice plants by Glomus intraradices does not affect the arbuscular mycorrhizal symbiosis. New Phyto/ 2010, 188(2):597-614

81. Tarkka MT, Herrmann S, Wubet T, Feldhahn L, Recht S, Kurth F, Mailander S, Bonn M, Neef M, Angay O, Bacht M, Graf M, Maboreke H, Fleischmann F Grams TE, Ruess L, Schadler M, Brandl R, Scheu S, Schrey SD, Grosse I, Buscot F: OakContigDF159.1, a reference library for studying differential gene expression in Quercus robur during controlled biotic interactions: use for quantitative transcriptomic profiling of oak roots in ectomycorrhizal symbiosis. New Phytol 2013, 199(2):529-540.

82. Tisserant E, Kohler A, Dozolme-Seddas P, Balestrini R, Benabdellah K, Colard A, Croll D, Da Silva C, Gomez SK, Koul R, Ferrol N, Fiorilli V, Formey D, Franken P, Helber N, Hijri M, Lanfranco L, Lindquist E, Liu Y, Malbreil M, Morin E, Poulain J, Shapiro H, van Tuinen D, Waschke A, Azcon-Aguilar C, Becard G, Bonfante P, Harrison MJ, Küster $\mathrm{H}$, et al: The transcriptome of the arbuscular mycorrhizal fungus Glomus intraradices (DAOM 197198) reveals functional tradeoffs in an obligate symbiont. New Phytol 2012, 193(3):755-769.

doi:10.1186/1471-2164-15-747

Cite this article as: Zhao et al.: Deep sequencing-based comparative transcriptional profiles of Cymbidium hybridum roots in response to mycorrhizal and non-mycorrhizal beneficial fungi. BMC Genomics 2014 15:747.

\section{Submit your next manuscript to BioMed Central and take full advantage of:}

- Convenient online submission

- Thorough peer review

- No space constraints or color figure charges

- Immediate publication on acceptance

- Inclusion in PubMed, CAS, Scopus and Google Scholar

- Research which is freely available for redistribution 